\title{
An intelligent approach to predicting the effect of nanoparticle mixture ratio, concentration and temperature on thermal conductivity of hybrid nanofluids
}

\author{
Ifeoluwa Wole-Osho ${ }^{1} \cdot$ Eric C. Okonkwo ${ }^{1,2} \cdot$ Humphery Adun $^{1} \cdot$ Doga Kavaz $^{3} \cdot$ Serkan Abbasoglu $^{1}$
}

Received: 21 November 2019 / Accepted: 17 March 2020 / Published online: 29 March 2020

(c) The Author(s) 2020

\begin{abstract}
Hybrid nanofluids are better heat transfer fluids than conventional nanofluids because of the combined properties of two or more nanoparticles. In this study, the thermal conductivity of $\mathrm{Al}_{2} \mathrm{O}_{3}-\mathrm{ZnO}$ nanoparticles suspended in a base fluid of distilled water is investigated. The experiments were conducted for three mixture ratios $(1: 2,1: 1$ and $2: 1)$ of $\mathrm{Al}_{2} \mathrm{O}_{3}-\mathrm{ZnO}$ nanofluid at five different volume concentrations of $0.33 \%, 0.67 \%, 1.0 \%, 1.33 \%$ and $1.67 \%$. X-ray diffractometric analysis, X-ray fluorescence spectrometry and scanning electron microscopy were used to characterise the nanoparticles. The highest thermal conductivity enhancement achieved for $\mathrm{Al}_{2} \mathrm{O}_{3}-\mathrm{ZnO}$ hybrid nanofluids with 1:2, 1:1 and 2:1 $\left(\mathrm{Al}_{2} \mathrm{O}_{3}: \mathrm{ZnO}\right)$ mixture ratios was $36 \%, 35 \%$ and $40 \%$, respectively, at volume concentration $1.67 \%$. The study observed the highest thermal conductivity for $\mathrm{Al}_{2} \mathrm{O}_{3}-\mathrm{ZnO}$ nanofluid was achieved at a mixture ratio of 2:1. A "deeping" effect was observed at a mixture ratio of 1:1 representing the lowest value of thermal conductivity within the considered range. The study proposed and compared three models for obtaining the thermal conductivity of $\mathrm{Al}_{2} \mathrm{O}_{3}-\mathrm{ZnO}$ nanofluids based on temperature, volume concentration and nanoparticle mixture ratio. A polynomial correlation model, the adaptive neuro-fuzzy inference system model and an artificial neural network model optimised with three different learning algorithms. The adaptive neuro-fuzzy inference system model was most accurate in forecasting the thermal conductivity of the $\mathrm{Al}_{2} \mathrm{O}_{3}-\mathrm{ZnO}$ hybrid nanofluid with an $R^{2}$ value of 0.9946 .
\end{abstract}

Keywords Nanoparticles $\cdot$ Alumina $\cdot$ Zinc oxide $\cdot$ Hybrid nanofluids $\cdot$ Thermal conductivity

\begin{tabular}{ll}
\multicolumn{2}{l}{ List of symbols } \\
$h$ & Nanolayer thickness $(\mathrm{m})$ \\
$k$ & Thermal conductivity $\left(\mathrm{W} \mathrm{m}^{-1} \mathrm{~K}^{-1}\right)$ \\
$R$ & Mixture ratio of $\mathrm{Al}_{2} \mathrm{O}_{3}$ \\
$r$ & Radius of nanoparticle $(\mathrm{m})$ \\
RMS & Root mean square \\
$R^{2}$ & Coefficient of determination \\
$T$ & Temperature
\end{tabular}

Eric C. Okonkwo

eokonkwo@hbku.edu.qa

1 Department of Energy Systems Engineering, Cyprus International University, Haspolat, Nicosia, North Cyprus, via Mersin-10, Turkey

2 Division of Sustainable Development, College of Science and Engineering, Hamad Bin Khalifa University, Education City, Qatar Foundation, Doha, Qatar

3 Department of Bioengineering, Cyprus International University, Haspolat, Nicosia, North Cyprus, via Mersin-10, Turkey

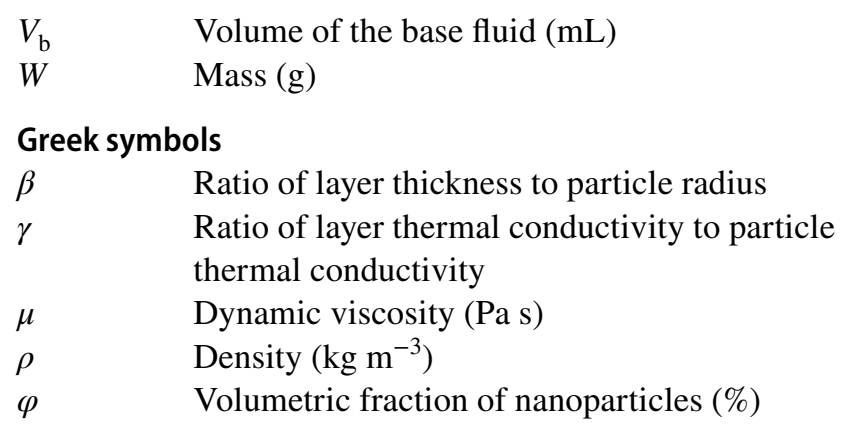




\begin{tabular}{|c|c|}
\hline \multicolumn{2}{|c|}{ Abbreviations } \\
\hline ANFIS & Adaptive neuro-fuzzy inference system \\
\hline ANN & Artificial neural network \\
\hline BR & Bayesian regularisation \\
\hline ASHRAE & $\begin{array}{l}\text { American Society of Heating, Refrigeration } \\
\text { and Air-Condition Engineers }\end{array}$ \\
\hline ASTM & American Society for Testing and Materials \\
\hline Conc & Concentration \\
\hline JCPDS & $\begin{array}{l}\text { Joint Committee on Powder Diffraction } \\
\text { Standards }\end{array}$ \\
\hline LVM & Levenberg-Marquardt backpropagation \\
\hline SCG & Scaled conjugate gradient \\
\hline SEM & Scanning electron microscope \\
\hline XRD & $\mathrm{X}$-ray diffraction \\
\hline Vol. & Volume \\
\hline \multicolumn{2}{|c|}{ Chemical formula } \\
\hline $\mathrm{Al}_{2} \mathrm{O}_{3}$ & Aluminum oxide \\
\hline $\mathrm{CuO}$ & Copper oxide \\
\hline EG & Ethylene glycol \\
\hline $\mathrm{SiO}_{2}$ & Silicon oxide \\
\hline $\mathrm{ZnO}$ & Zinc oxide \\
\hline
\end{tabular}

\section{Introduction}

Nanofluids are a colloidal suspension of nanometer-sized materials in base fluids. Nanofluids have unique characteristics when compared to conventional fluids, making them highly applicable in diverse fields [1]. Certain areas where nanotechnology have gained application are in microelectronics, medical and health technology, aerospace, agriculture [2] and even the decomposition of pollutants in the environment [3]. Nanofluids are effective heat transfer fluids due to their high thermal conductivity properties which have made them useful in industrial devices like industrial heat exchangers, solar heat exchangers and solar collectors [4].

Heat transfer is an essential field of science because of its varied application in the effective operation of various energy devices [5]. Improving the known heat transfer mediums enables us to manage and efficiently use energy. Regular heat transfer fluids like water, oil and glycols have inherently low thermal conductivity, which significantly limits their heat transfer abilities [6]. However, since the advent of nanoscience, a new category of fluids with significantly improved thermal conductivity properties has been realised. These nanofluids are solid dispersions of nanoparticles (particles with an average size of less than $100 \mathrm{~nm}$ ) in a base fluid [7]. This nanofluid can be manufactured by either one-step chemical method [8], a one-step physical method [9] or a two-step method [10]. The nanofluids can also be classified into either conventional or hybrid nanofluids [11]. Conventional nanofluids are nanofluids that contain single material particle dispersions, while hybrid nanofluids contain multiple material particle dispersions within the fluids. The dispersion of nanoparticles within the based fluid improves the thermal conductivity of the resultant nanofluid when compared to the based fluids.

The most common technique used to measure the thermal conductivity of nanofluid is the transient hot-wire technique proposed in 1931 [12]. Several review papers have been written on the thermal conductivity of various nanofluids [11], and the effective parameters which influence the thermal conductivity of the nanofluids [13]. Bashirnezhad et al. [14] in their review of experimental studies on the thermal conductivity of nanofluids identified about ten factors that affect the thermal conductivity of nanofluids. These factors include the size and shape of the nanoparticles, the nanoparticle volume fraction, the temperature and stability of the suspension, the clustering of nanoparticles, the $\mathrm{pH}$ and the use of surfactants. Of these parameters, there have been several studies to investigate the effects of volume concentration $(\varphi)$ on the thermal conductivity of nanofluids [15]. Izadkhah et al. [16] use classical molecular dynamics simulations to investigate the stability and thermal conductivity of graphene-oxide EG water nanofluids. Their simulation, which was carried out for 3\%, 4\% and 5\% graphene-oxide nanosheet, showed an increase in thermal conductivity by $24 \%, 28 \%$ and $33 \%$, respectively. Kumar et al. investigated the effect on volume concentration on $\mathrm{Al}_{2} \mathrm{O}_{3}$-water, $\mathrm{Al}_{2} \mathrm{O}_{3}$ ethylene glycol (EG) and $\mathrm{Al}_{2} \mathrm{O}_{3}$-paraffin nanofluids and observed that the thermal conductivity of each of the nanofluids increased with an increase in volume concentration between $0.01 \%$ and $0.08 \%$. Agarwal et al. [17] also performed a similar investigation using $\mathrm{CuO}$ water, $\mathrm{CuO} / \mathrm{EG}$ and $\mathrm{CuO} /$ engine oil nanofluids. Their experiment also recorded that thermal conductivity increases with an increase in volume concentration between 0.25 and $2 \%$. Esfe et al. [18] investigated the thermal conductivity of $\mathrm{Al}_{2} \mathrm{O}_{3}$ water nanofluid at volume concentration between $0.25 \%$ and $5 \%$. They performed a sensitivity analysis and concluded that both the nanoparticle concentration and temperature of the suspension affected the thermal conductivity of the nanofluids. Similar studies using $\mathrm{SiO}_{2}$ [19], graphene [20] and other conventional nanofluids have provided a similar result.

More recently, the concept of hybrid nanofluids has found the attention of researchers. A hybrid nanofluid is formed by the dispersion of two or more nanoparticles into a base fluid. The idea is that the combined thermal properties of both nanoparticles would further enhance the properties of the resultant nanofluids better than when one nanoparticle material is used. Gangadevi and Vinayagam [21], compared the thermal conductivity and viscosity performance of $\mathrm{CuO} /$ water, $\mathrm{Al}_{2} \mathrm{O}_{3} /$ water and $\mathrm{Cuo}-\mathrm{Al}_{2} \mathrm{O}_{3}$ /water nanofluids. Their results showed that the thermal conductivity was enhanced at $11.2 \%, 12.16 \%$ and $21 \%$ for $\mathrm{Al}_{2} \mathrm{O}_{3}$ /water, 
$\mathrm{CuO} /$ water and $\mathrm{CuO}-\mathrm{Al}_{2} \mathrm{O}_{3}$ /water nanofluids, respectively, at $0.2 \%$ volumetric concentrations of the nanoparticles. Testing the nanofluids on a hybrid solar collector, the authors found that the hybrid nanofluids were more effective in reducing the temperature of the collector, which in turn improved its overall efficiency of the system. Toghraie et al. [22], synthesized ${\mathrm{ZnO}-\mathrm{TiO}_{2}}_{2} \mathrm{EG}$ hybrid nanofluid and measured its thermal conductivity at volume concentrations between $0.25 \%$ and $3 \%$. Results obtained from their experiment show that an increase in volume concentration increased the thermal conductivity of the hybrid. Esfahani et al. [23] experimentally investigated the thermal conductivity of $\mathrm{ZnO}-\mathrm{Ag}$ water hybrid at a nanoparticle mixture ratio of 50:50. Their experiment also noticed that volume concentration was directly proportional to the increase in thermal conductivity recorded. A lot of other hybrid nanofluids has been experimentally investigated and have provided similar relationships between thermal conductivity and volume concentration [24]. Therefore, in both conventional and hybrid nanofluids, the thermal conductivity increases with an increase in volume concentration.

Esfe et al. [25] studied the effect of nanoparticle size on the thermal conductivity of nanofluids using Fe nanoparticles with an average size of $37 \mathrm{~nm}, 71 \mathrm{~nm}$ and $98 \mathrm{~nm}$. The study reported that the thermal conductivity of nanofluids improved with the reduction in nanoparticle size. In a similar study performed by Chevalier et al. [26], using $\mathrm{SiO}_{2}$ particles with an average diameter of $35 \mathrm{~nm}, 94 \mathrm{~nm}$ and $190 \mathrm{~nm}$. They also observed the direct influence of particle size on thermal conductivity of $\mathrm{SiO}_{2}$ alcohol nanofluid, as an increase in particle size decreased thermal conductivity at constant volume concentration and temperature.

Aggregation also affects the thermal conductivity of nanofluids. Hong and Kim [27] studied the effect of aggregation on the thermal conductivity of $\mathrm{Al}_{2} \mathrm{O}_{3}$ nanofluid. They induced aggregation in the nanofluid by adding of $\mathrm{NaCl}$ solution to the fluid. Their experiment observed that the thermal conductivity increased with an increase in particle aggregation. The maximum thermal conductivity enhancement observed was $22 \%$. Also, Prasher et al. [28] modelled particle aggregation for three-level homogenisation theory using Monte Carlo numerical calculations. The study showed that fractal aggregates improve the thermal conductivity of nanofluids, and there is an active correlation between thermal conductivity enhancement and the chemical dimension of the aggregates. Parameshwaran and Kalaiselvam [29] studied the effect of aggregation on the thermal conductivity of hybrid nanofluid by dispersing silver-titania hybrid nanocomposite particles in a phase change material (dimethyl adipate). The experiment observed that particle aggregation is vital in the thermal conductivity enhancement of nanofluids [29].
As colloidal particles are suspended within a base fluid, an interfacial layer forms around the particles. Interfacial layers are essential in understanding the particle fluid relation, determining the structure of the liquid layering around the particle and the effects on the thermal conductivity of nanofluids. Gerardi et al. [30], experimentally measured the thickness of the interfacial layer around $\mathrm{Al}_{2} \mathrm{O}_{3}$ nanoparticles in water and observed layer thickness to be $1.4 \mathrm{~nm}$. The thermal conductivity of the interfacial layer was simulated by applying molecular dynamics simulation, and it was observed that the thermal conductivity of the interfacial layer could be 1.6-2.5 times higher than that of the base fluid. Also, the thermal conductivity is dependent on the strength of solid-liquid interaction [31].

Several theoretical models have been proposed to account for the interfacial layers in nanofluids. Yu and Choi [32] improved on Maxwell's model [33] to account for the interfacial layer. Also, Xue [34], Xie et al. [35] and Koo et al. [36] all proposed models that accounted for the effect of the interfacial layers.

As stated, theoretical models of predicting thermal conductivity are limited in accuracy, mainly due to the number of different variables that appear to affect the thermal conductivity of nanofluids. Many researchers have proposed various correlation models to ascertain the thermal conductivity of specific nanofluids, more recently, artificial neural networks have also presented an alternative to predicting the nanofluids thermal conductivity. There have been different artificial intelligence approaches used to predict the thermal conductivity of nanofluids; these include adaptive neuro-fuzzy inference system (ANFIS), multilayer perceptron artificial neural network (MLP-ANN), radial basis function artificial neural network (RBF-ANN), least-square support vector machine (LSSVM), least-square support vector machine-genetic algorithm (LSSVM-GA), etc. Different optimisation algorithms have been used to improve the accuracy of the artificial intelligence approaches; they include Bayesian regularisation (BR), Levenberg-Marquardt (LVM), particle swarm optimisation (PSO) and scaled conjugate gradient (SCG).

Aybar et al. [37] conducted a review of the many predictive models that have been presented for obtaining the thermal conductivity of various nanoparticles. Zadkhast et al. [38] investigated the thermal conductivity of MWCNT-CuO/ water nanofluids. A 30.8\% enhancement was witnessed with the use of the nanofluids at a $0.6 \%$ volume concentration. The authors also proposed a correlation for obtaining the thermal conductivity of MWCNT-CuO/water nanofluids. Esfe et al. [39] proposed a model based on the Jang and Choi model [40] for predicting the thermal conductivity of MWCNT-MgO/EG water nanofluids. Measuring their predicted results with the experimental data showed that their model was below $5 \%$ of the margin of deviation. 
Moosavi et al. [41] collected 483 data points from thermal conductivity experiments of 18 different conventional nanofluids. The data points collected were used as the training and testing set in ANN-MLP, ANN-RBF, GMDH and ANFIS predicting methods. The study observed that ANFIS was the best model in predicting the thermal conductivity of conventional nanofluids. Li et al. [42] trained an artificial neural network using $70 \%$ of the 48 sets of experimental data obtained from $\mathrm{Al}_{2} \mathrm{O}_{3}$-EG nanofluids. The ANN was more accurate than the proposed correlation model, with an $R^{2}$ of 0.9997. Razavi et al. [43] used particle swarm-optimised LSSVM and ANFIS to predict the thermal conductivity of nanofluids. In the study, 1109 data points were collected from experimental studies and were used to train and test the neural network. The study concludes that the LSSVM algorithm showed the most accurate performance in predicting the thermal conductivity nanofluids.

The thermal conductivity of $\mathrm{Al}_{2} \mathrm{O}_{3}-\mathrm{CuO}$ EG/water hybrid nanofluids at 11 different mixture ratios was measured; when ANN was used to forecast the values of thermal conductivity, $R^{2}$ values were equal to 0.9846 [44].

MLP-ANN, ANFIS, LSSVM and RBF-ANN methods were used to forecast the thermal conductivity of $\mathrm{TiO}_{2}$ water nanofluids [45]. Similar to Razavi et al. [43] study, this study also observed that LSSVM produced the best predictive results showing the least deviation factor. It is important to note that in the sensitivity analysis, the volume fraction of nanoparticles had a direct impact on the results. Peng et al. [46] used a feedforward MLP-ANN to predict the thermal conductivity of $\mathrm{Al}_{2} \mathrm{O}_{3}-\mathrm{Cu}$ EG hybrid nanofluids. Using only a single hidden layer, the MLP-ANN showed an $R^{2}$ value equal to 0.99974. Alarifi et al. [47] measured the thermal conductivity behaviour of $\mathrm{Al}_{2} \mathrm{O}_{3}-\mathrm{MWCNT} /$ thermal oil hybrid nanofluids; in predicting the behaviour of the nanofluids, the ANFIS was optimised with genetic algorithms (GA) and particle swarm optimisation. The study concluded that while both models could predict thermal conductivity in the hybrid to a significant degree of accuracy; the ANFIS optimised with PSO had a better predictive performance compared to the ANFIS model optimised by GA.

From a review of the literature, we can see that several researchers have carried out numerous experiments measuring the thermal conductivity of different nanofluids. However, until an acceptable theoretical approach is presented to calculate the thermal conductivity of nanofluids, more thermal conductivity experimental measurement are still needed as new nanofluids are developed. As a result, this study investigates the thermal conductivity of $\mathrm{Al}_{2} \mathrm{O}_{3}-\mathrm{ZnO}$ water hybrid nanofluid at five different nanoparticle concentrations and at three mixture ratios of $2: 1,1: 1$ and $1: 2$ $\left(\mathrm{Al}_{2} \mathrm{O}_{3}: \mathrm{ZnO}\right)$. These nanoparticles were used in the synthesis of hybrid nanofluids because they are chemically inert, cheap and can show good stability and dispersion behaviour.
To the best of the author's knowledge, no other study has been done on the thermal conductivity of $\mathrm{Al}_{2} \mathrm{O}_{3}-\mathrm{ZnO}$ water hybrid nanofluids. Also, the effect of nanoparticles mixture ratio in the hybrid was particularly studied, to confirm if the "deeping" effect witnessed at 1:1 mixture ratio for both $\mathrm{Al}_{2} \mathrm{O}_{3}-\mathrm{CuO}$ EG/water [44] and $\mathrm{SiO}_{2}-\mathrm{TiO}_{2}$ EG/water [48] nanofluids apply to $\mathrm{Al}_{2} \mathrm{O}_{3}-\mathrm{ZnO}$ water hybrid nanofluids. The study also presents and compares intelligent ways to predict the thermal conductivity of the hybrid nanofluid using ANFIS and MLP-ANN. Consequently, the input parameters in this study were the temperature of the nanofluid, the volume concentration of particles and the mixture ratio of particles. Finally, the performance of the predictive models was evaluated using statistical indices.

\section{Hybrid nanofluid synthesis, characterisation and thermal conductivity measurement technique}

Hybrid nanofluids have been shown to have better thermal properties than conventional nanofluids. Therefore, this study uses $\mathrm{ZnO}$ and $\mathrm{Al}_{2} \mathrm{O}_{3}$ nanoparticles to synthesis a hybrid nanofluid. The idea is that the combined thermal properties of both nanoparticles would further enhance the properties of the resultant nanofluids. The choice of $\mathrm{Al}_{2} \mathrm{O}_{3}$ nanoparticles in this study is due to its extensive investigation in the literature along with its relatively cheap cost of purchase $[49,50]$. $\mathrm{ZnO}$ nanoparticles on the other is utilised because it has very good optical properties, enhanced bandgap energy along with its environmental friendliness and its stability nature [1].

$\mathrm{Al}_{2} \mathrm{O}_{3}$ nanoparticles are synthesised using the technique presented in Wole-Osho et al. [51]. $\mathrm{Al}_{2} \mathrm{O}_{3}$ produced from this synthesis method produced nanoparticles with an average particle size of $29 \mathrm{~nm}$. Also, another synthesis method proposed by Romadhan et al. [52] was used to produce $\mathrm{ZnO}$ nanoparticles with an average size of $70 \mathrm{~nm}$. The properties of both nanoparticles are presented in Table 1. Figure 1a, $b$ shows the SEM image of $\mathrm{Al}_{2} \mathrm{O}_{3}$ and $\mathrm{ZnO}$ nanoparticles. The SEM images show spherical patterns in both $\mathrm{Al}_{2} \mathrm{O}_{3}$ and

Table 1 Properties of nanoparticles used

\begin{tabular}{lll}
\hline Properties & Specifications & \\
\hline Molecular formula & $\mathrm{ZnO}$ & $\mathrm{Al}_{2} \mathrm{O}_{3}$ \\
Nanoparticle shape & Spherical & Spherical \\
Nanoparticle average size & $70 \mathrm{~nm}$ & $29 \mathrm{~nm}$ \\
Density & $5.6 \mathrm{~g} \mathrm{~cm}^{-3}$ & $3.8 \mathrm{~g} \mathrm{~cm}^{-3}$ \\
Appearance & White & White \\
Purity & $>87 \%$ & $>98.5 \%$ \\
\hline
\end{tabular}


Fig. 1 SEM characterisation of dispersed $\mathbf{a} \mathrm{Al}_{2} \mathrm{O}_{3}$ and $\mathbf{b} \mathrm{ZnO}$ in water

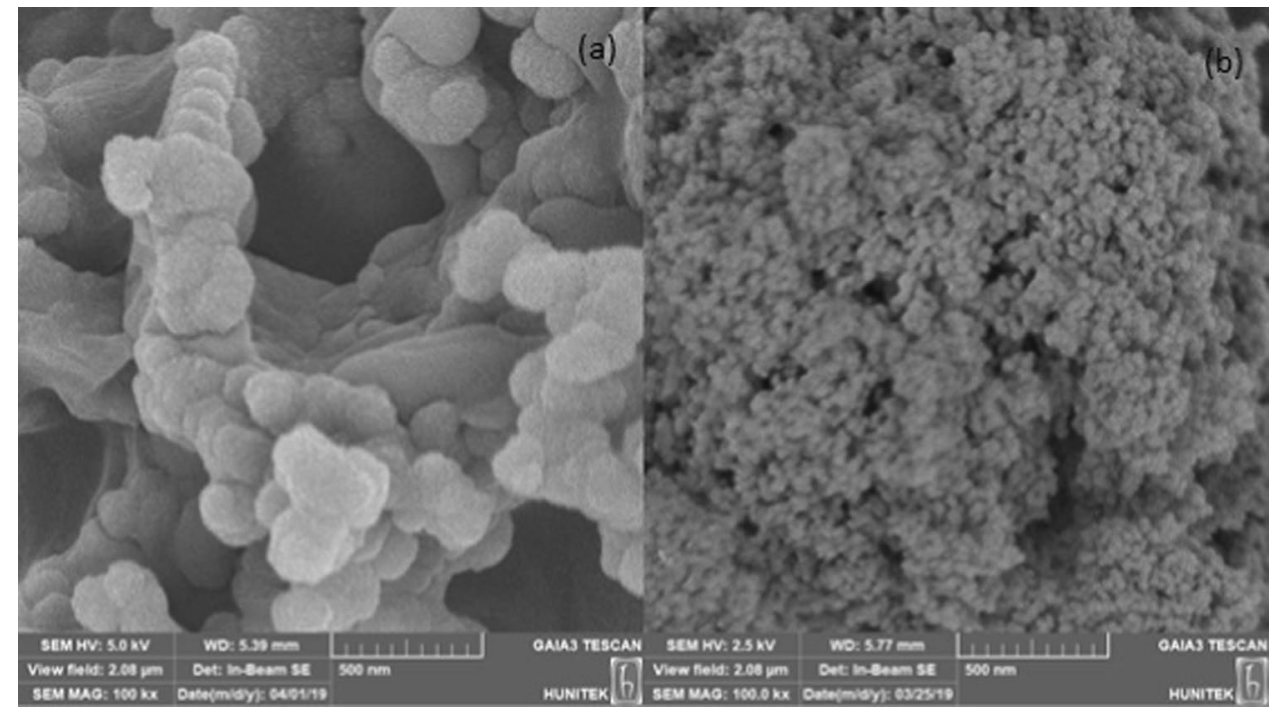

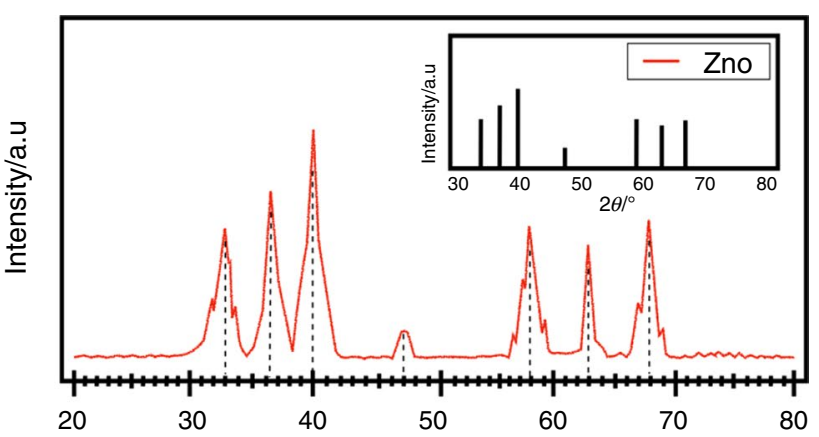
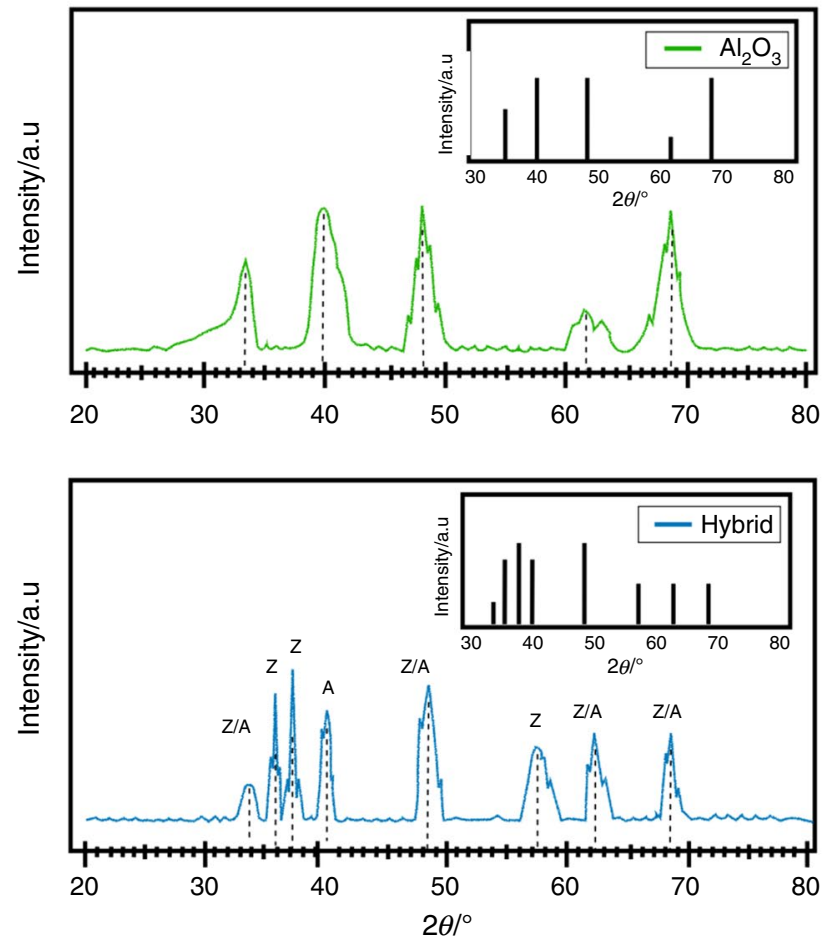

Fig. 2 XRD characterisation for $\mathrm{ZnO}, \mathrm{Al}_{2} \mathrm{O}_{3}$ and $\mathrm{Al}_{2} \mathrm{O}_{3}-\mathrm{ZnO}$ water nanoparticles

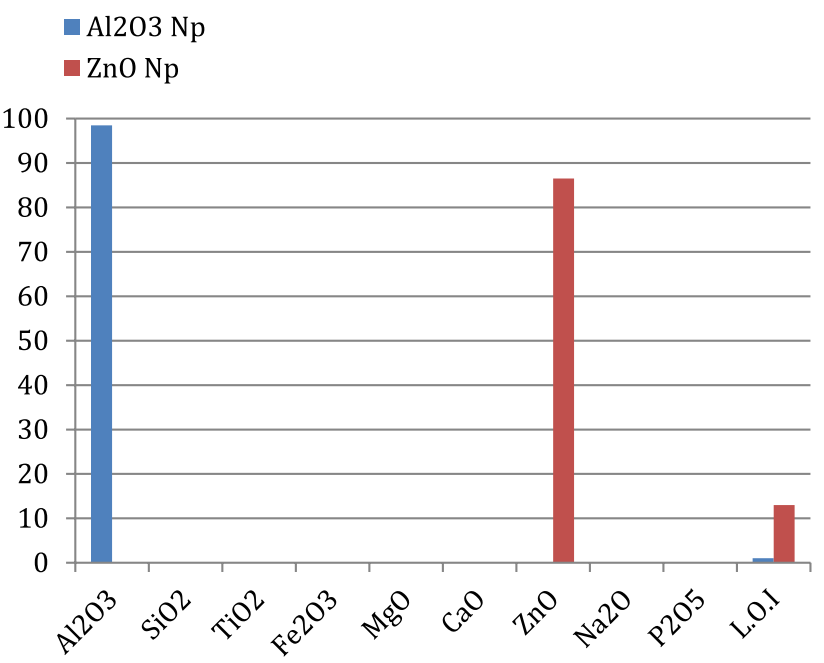

Fig. $3 \mathrm{XRF}$ analysis of nanoparticles

$\mathrm{ZnO}$ nanoparticles; some agglomeration can be observed in Fig. 1a, b.

Figure 2 shows the XRD analysis of the nanofluids and their peak intensities: the red line, green line and blue lines represent the observed pattern obtained for the $\mathrm{ZnO}$, $\mathrm{Al}_{2} \mathrm{O}_{3}$ and the hybrid nanofluids, respectively. $\mathrm{Cu} \mathrm{K \alpha}$ radiation $(1.5406 \AA)$ was used to record the diffraction, and the XRD pattern was taken at $2 \theta$ for values ranging from $20^{\circ}$ to $80^{\circ}$. The observable peaks have been referenced with the $\mathrm{ZnO}$ wurtzite structure (JCPDS Data Card No: 36-1451), and they showed great similarities with the reference data. The XRD analysis for $\mathrm{Al}_{2} \mathrm{O}_{3}$ nanoparticles (green line) appeared to peak at $32^{\circ}, 39^{\circ}, 48^{\circ}, 57^{\circ}, 62^{\circ}$ and $68^{\circ}$; this is in accordance with the all corresponding characteristic reflection of (220), (222), (400), (422), (511) and (440) which is in agreement with the JCPDS card no. 
02-1420. The peaks observed tend to show that the nanoparticles have a high degree of purity; the XRF analysis also supports this.

X-ray fluorescence spectrometer (Rigaku XRF, ZSX Primus II) was used in determining the constituent elements of the nanofluids. The physical characterisation of the nanoparticles was evaluated by using the XRF. Based on X-ray fluorescence analyses, $\mathrm{Al}_{2} \mathrm{O}_{3}$ is about $98.5 \%$ pure, and $\mathrm{ZnO}$ is about $87 \%$ pure, L.O.I (loss on "eye" ignition) accounts for $1.03 \%$ in $\mathrm{Al}_{2} \mathrm{O}_{3}$ and $12 \%$ in $\mathrm{ZnO}$, as seen in Fig. 3 .

The hybrid nanofluids were synthesised at volume concentrations of $0.33 \%, 0.67 \%, 1.0 \%, 1.33 \%$ and $1.67 \%$ and mixtures ratios of $1: 1,2: 1$ and $1: 2\left(\mathrm{Al}_{2} \mathrm{O}_{3}: \mathrm{ZnO}\right)$ using the two-step method. Zeta potential analysis was done at five $\mathrm{pH}$ values of $1,4,7,10$ and 12 . The preparation technique and the stability performance of the nanofluid are presented in Wole-Osho et al. [51].

The thermal conductivity readings for the samples were measured using the KD2 pro II analyser, according to the ASTM D7896-19 [53]. The readings were taken for temperatures ranging from 25 to $65^{\circ} \mathrm{C}$. These readings from the $\mathrm{KD} 2$ analyser were verified by taking the readouts of both deionised water and glycerine before testing. The measurements from the digital readout were repeated three times, and the average value from the sets of readouts was taken. Measurements were taken between fixed time intervals to reduce the error that may occur as a result of temperature variation on the sensor when in direct contact with the nanofluids sample.

\section{Uncertainty analysis}

In determining the uncertainty of the experimental results obtained in this study, the measurement errors for thermal conductivity, temperature and mass were considered. The thermal conductivity of nanofluids was studied using the KD2 Pro analyser, the mass of the nanoparticles was measured by precision balance PL602E (Mettler Toledo), and the temperature was measured using a resistive temperature detector (DHT11). Experimental uncertainty was determined as follows:

$U_{\mathrm{e}}= \pm \sqrt{\left(\frac{\Delta k}{k}\right)^{2}+\left(\frac{\Delta W}{W}\right)^{2}+\left(\frac{\Delta T}{T}\right)^{2}}$

The accuracy of the KD2 Pro Analyser was $\pm 5 \%$. The accuracy of the RTD was $\pm 0.1^{\circ} \mathrm{C}$. The precision balance was accurate to about $\pm 0.05 \mathrm{~g}$. Experiment uncertainty was, therefore, less than $2 \%$.

\section{Models to predict the thermal conductivity of nanofluids}

Several different models have been proposed to predict the thermal conductivity of nanofluids. However, more research is required, especially for hybrids, because classical models have proven to be inadequate in predicting thermal conductivity in hybrids nanofluids [54].

\section{Theoretical models for thermal conductivity prediction}

Maxwell [33] first postulated the theoretical understanding of the thermal conductivity of fluids containing colloidal dispersions. However, this model has been fairly inaccurate in predicting the thermal conductivity of nanofluids. In the last two decades, there have been several proposed theoretical models to predict the thermal conductivity of nanofluids; however, many of these models are still relatively inaccurate.

As observed in Table 2, these classical models cannot adequately predict the thermal conductivity of nanofluids over an extended range of values. The limitations occur because the models fail to consider many of the parameters that potentially influence the thermal conductivity of nanofluids. These parameters include temperature, particle size, nanoparticles cluster, agglomeration, Kapitza resistance, particle Brownian motion, particle distribution and the interfacial layer between particle fluid composites, etc.

Researchers have postulated several other models to improve on these classical models taken into account some of these earlier mentioned parameters. The role of the interfacial layer is essential to understanding the thermal conductivity in nanofluids. Wang et al. [55] put forward a model to account for the interfacial layer by applying the effective medium approximation; however, this model still appears inaccurate when compared with experimental data.

Recently, many researchers have opted to use both statistical modelling technique and artificial intelligence techniques to predict the thermal conductivity of nanofluids.

\section{Adaptive neuro-fuzzy inference system (ANFIS) approach}

Jang initially proposed the adaptive neuro-fuzzy inference system (ANFIS) approach in the 1990s [62]. ANFIS applies fuzzy "if-then" rules to determine the relationship between input and output variables. The combination of both a fuzzy inference system (FIS) and artificial neural network (ANN) allows for the system to describe the thermal conductivity behaviour of the complex system. ANFIS is structured such that there are five layers, as observed in Fig. 4. 
Fuzzy membership functions were employed to study the thermal conductivity values. The membership function determines the degree of exactness; rather a switch value (TRUE or FALSE, 0 or 1) its value tends to range between 0 and 1 [63]. ANFIS is premised on the rationale that the fact that, different rules cannot have the same output membership function and that the number of membership functions must be equal to the number of rules. With initial if-then instructions, connect by certain rules. For instance, if input values are $x$ and $y$, two if-then rules are generated.

Rule 1: if $x$ is $A_{1}$ and $y$ is $B_{1}$ then $f=p_{1} x+q_{1} y+r_{1}$

Rule 2: if $x$ is $A_{2}$ and $y$ is $B_{2}$ then $f=p_{2} x+q_{2} y+r_{2}$

Layer 1: In this layer, all the nodes are adaptive; the output from the nodes in layer one is fuzzy by the application of membership functions. The Gaussian membership function can be seen in Eq. (4).

$O_{\mathrm{i}}^{1}=\beta(X)=e^{\left(\left(-\frac{1}{2}\right)\left(\frac{(X-Z))^{2}}{\sigma^{2}}\right)\right)}$

Layer 2: In this layer, the masses are being determined based on initial rules:

$O_{\mathrm{i}}^{2}=W_{\mathrm{i}}=\beta_{\mathrm{Ai}}(X) \beta_{\mathrm{Bi}}(X)$

Layer 3: In this layer, average mass values are determined:

$O_{\mathrm{i}}^{3}=\frac{W_{\mathrm{i}}}{\sum W_{\mathrm{i}}}$

Layer 4: In this layer, a determinative function is reached to computer average mass values:

$O_{\mathrm{i}}^{4}=\bar{W}_{\mathrm{i}} f_{\mathrm{i}}=\overline{W_{\mathrm{i}}}\left(m_{\mathrm{i}} X_{1}+n_{\mathrm{i}} X_{2}+r_{\mathrm{i}}\right)$

Layer 5: In this layer, the sum of the outputs is determined:

$O_{\mathrm{i}}^{5}=\sum \overline{W_{\mathrm{i}}} f_{\mathrm{i}}=\overline{W_{\mathrm{j}}} f_{\mathrm{i}}+\overline{W_{\mathrm{i}}} f_{\mathrm{i}}=\frac{\sum W_{\mathrm{j}} f_{\mathrm{i}}}{\sum W_{\mathrm{i}}}$

For the ANFIS analysis in this study, three (3) membership functions each in respect to the input variables (temperature, volume concentration and mixture ratio) were utilised.

\section{Artificial neural networks}

The operation of ANN is designed to imitate the learning process of the human brain. The ANN model comprises of a combination of connected units called neurons. The ANN 
Fig. 4 Schematic diagram for ANFIS

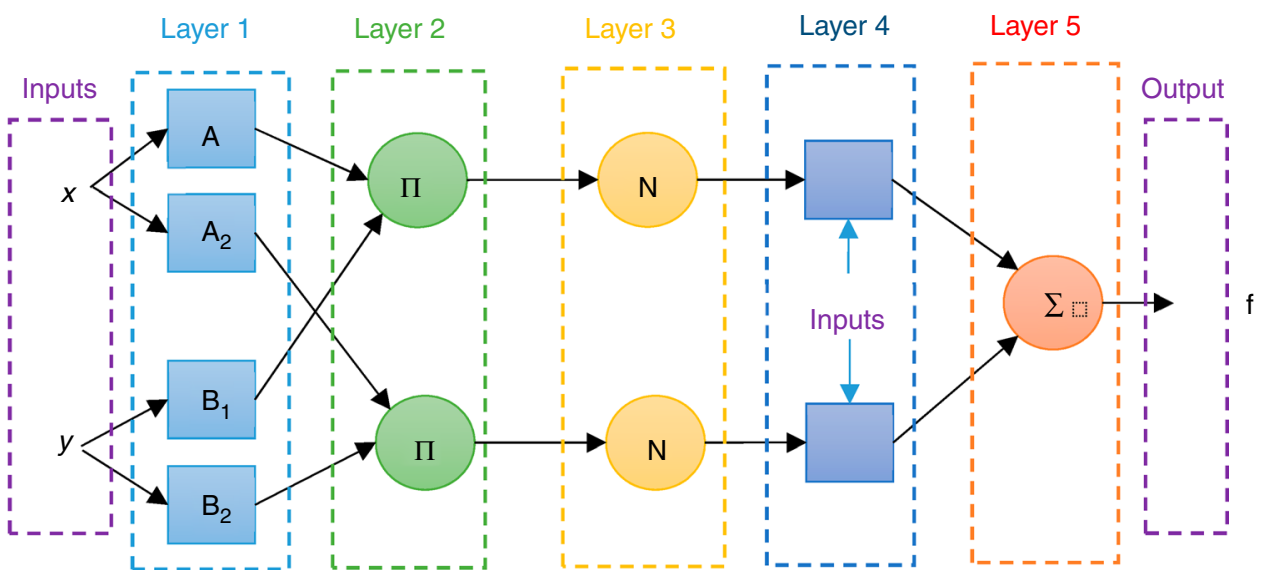

architecture also consists of the input layer, hidden layers and the output layer. A nonlinear transfer function in each node distributes the signals from one layer to the other. The neurons in the hidden layers multiply the masses $\left(w_{\mathrm{ij}}\right)$ with the sum of its input layers $\left(x_{\mathrm{i}}\right)$. The output layer is represented in Eq. (9).

$y_{\mathrm{j}}=f\left(\sum_{\mathrm{i}=0}^{\mathrm{d}^{\mathrm{i}-1}}\left(w_{\mathrm{ij}}^{1} x_{\mathrm{i}}^{1-1}\right)\right)$

$f=\frac{1}{1+e^{-\mathrm{x}}}$

where $l$ is the number of layers, $w_{\mathrm{ij}}^{\mathrm{l}}$ represents the masses in each layer $l$ with I input and $l$ layer, the dimension of the network is $d$ and $f$ is the threshold function, which is a sigmoid function.

For excellent predicting quality, the model and parameters need to be varied to choose the most efficient architecture. The different training algorithms used in this study are Levenberg-Marquardt backpropagation (LM), scaled conjugate gradient (SCG) and Bayesian regularisation (BR). Also, the number of neurons in the hidden layer in each algorithm is adjusted. Pre-processing of the dataset is important before training of the dataset as it helps to reach training faster and avoid getting stuck in local optima. All data are normalised between [0-1] before training and testing and are de-normalised afterwards.

$X_{\mathrm{n}}=\frac{\left(\left(X_{\text {actual }}-\text { Current_min }\right)\left(\mathrm{New}_{\max }-\mathrm{New}_{\min }\right)\right)}{\left(\text { Current }_{\max }-\text { Current }_{\min }\right)}+\mathrm{New}_{\min }$

$X_{\text {actual }}=$

$\frac{\left(\left(X_{\mathrm{n}}-\mathrm{New}_{\min }\right)\left(\text { Current }_{\max }-\mathrm{Current}_{\min }\right)\right)}{\left(\mathrm{New}_{\max }-\mathrm{New}_{\min }\right)}+$ Current $_{\min }$
Table 3 Training conditions of ANN model

\begin{tabular}{ll}
\hline Parameters & Settings \\
\hline Training pattern & $70 \%$ \\
Epoch & 1000 \\
Testing pattern & $30 \%$ \\
Learning rate & 0.1 \\
Number of hidden layers & 1 \\
Node in hidden layer & $5,10,15,20$ \\
Learning algorithm & LM, BR, SCG \\
Threshold function & Sigmoid \\
Performance function & $R^{2}$, RMSE, SSE \\
\hline
\end{tabular}

$X_{\mathrm{n}}$ represents the normalised dataset and $X_{\text {actual }}$ is the denormalised dataset. Table 3 shows the training conditions used in analysing the ANN prediction model.

The performance of each the ANN models is analysed using the $R^{2}$, root mean square (RMSE) and the sum of squared estimate error. Figure 5 shows the flowchart of the methodology of the ANN model analysis. $70 \%$ of the data are used in training and validating the ANN network, and the rest $30 \%$ which are unused in the training phase, made up for testing the model. Figure 6 shows the topology of the ANN model; the three input parameters used are temperature, volume fraction and mixture ratio, while the output is the thermal conductivity ratio.

$\operatorname{RMSE}=\sqrt{\frac{1}{N} \sum_{\mathrm{i}=1}^{\mathrm{N}}\left(k_{\text {exp }, \mathrm{i}}-k_{\text {pred,i }}\right)^{2}}$ 
Fig. 5 Flowchart of ANN modelling
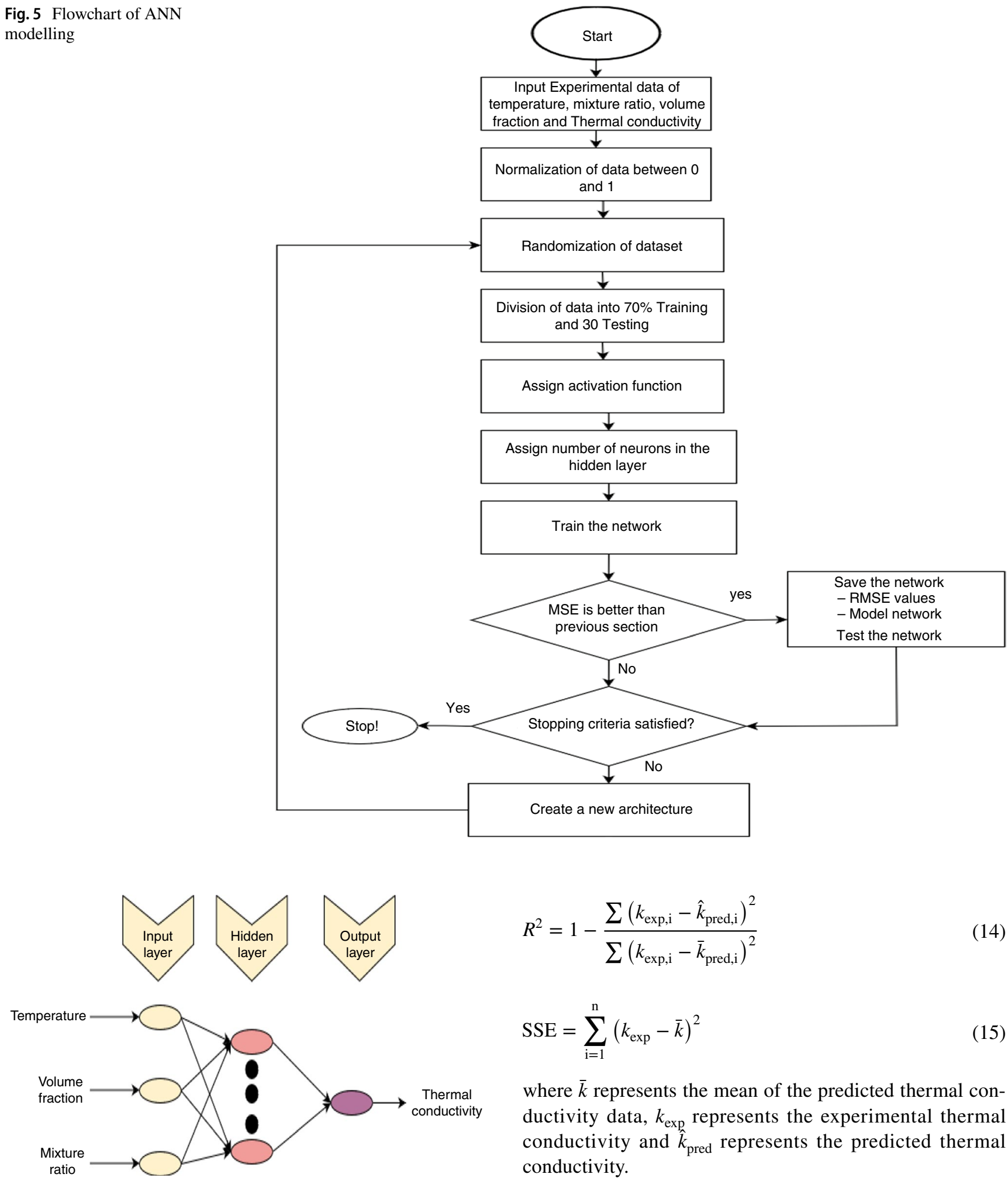

$R^{2}=1-\frac{\sum\left(k_{\text {exp,i }}-\hat{k}_{\text {pred,i }}\right)^{2}}{\sum\left(k_{\text {exp,i }}-\bar{k}_{\text {pred,i }}\right)^{2}}$

$\mathrm{SSE}=\sum_{\mathrm{i}=1}^{\mathrm{n}}\left(k_{\exp }-\bar{k}\right)^{2}$

where $\bar{k}$ represents the mean of the predicted thermal conductivity data, $k_{\text {exp }}$ represents the experimental thermal conductivity and $\hat{k}_{\text {pred }}$ represents the predicted thermal conductivity.

Fig. 6 Topology of the neural network model 
Fig. 7 Thermal conductivity comparison of water, $\mathrm{Al}_{2} \mathrm{O}_{3}$ and $\mathrm{ZnO}$ and hybrid nanofluids

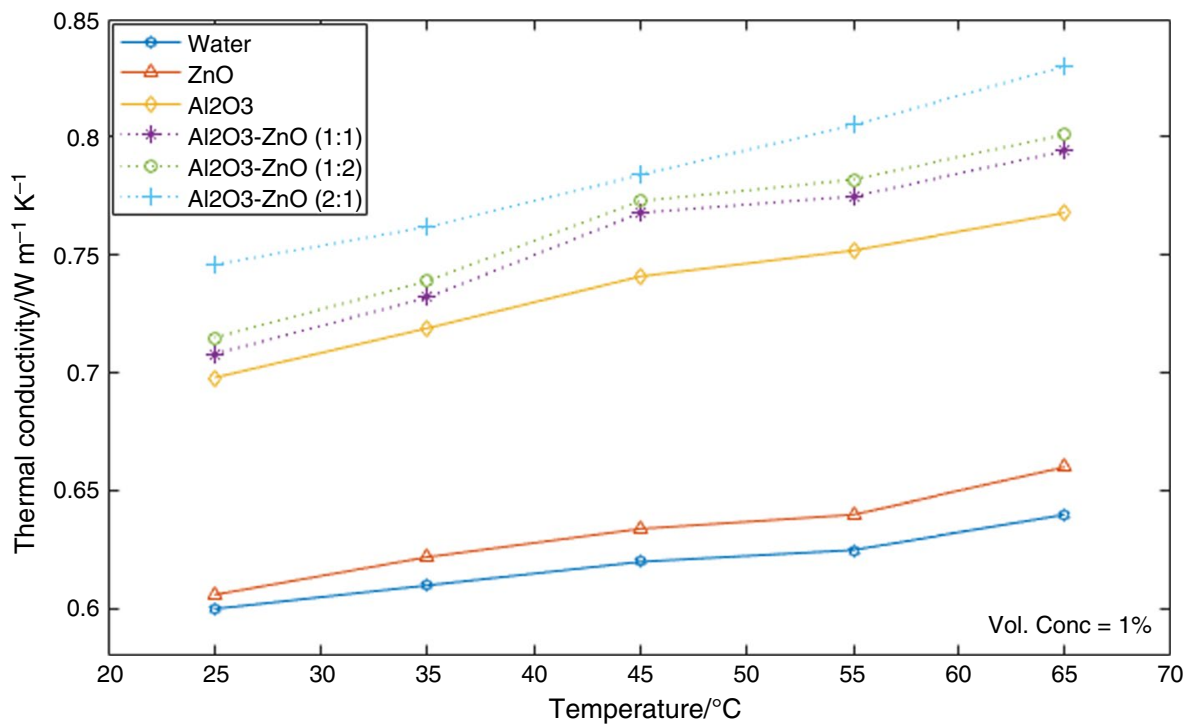

\section{Results and discussion}

Thermal conductivity measurement was taken for $\mathrm{Al}_{2} \mathrm{O}_{3}-\mathrm{ZnO}$ hybrid nanofluid at different mixture ratios and they include: $\mathrm{Al}_{2} \mathrm{O}_{3}: \mathrm{ZnO}(1: 1), \mathrm{Al}_{2} \mathrm{O}_{3}: \mathrm{ZnO}$ (1:2) and $\mathrm{Al}_{2} \mathrm{O}_{3}: \mathrm{ZnO}$ (2:1). The thermal conductivity values were also taken at five temperature ranges $\left(25^{\circ} \mathrm{C}, 35^{\circ} \mathrm{C}, 45^{\circ} \mathrm{C}, 55^{\circ} \mathrm{C}\right.$ and $\left.65^{\circ} \mathrm{C}\right)$ and five volume concentration values $(0.33 \%$, $0.67 \%, 1.0 \%, 1.33 \%$ and $1.67 \%)$. Thermal conductivity measurement was validated with ASHRAE [64] and compared with distilled water. An observed deviation between the measured data for water and that of ASHRAE was seen to be less than $1.5 \%$.

\section{Hybridisation effect}

Figure 7 shows the thermal conductivity of water, $\mathrm{Al}_{2} \mathrm{O}_{3}$, $\mathrm{ZnO}$ and the hybrid nanofluids at a volume concentration of $1 \%$ and a temperature range between 25 and $65^{\circ} \mathrm{C}$. Figure 7 shows that $\mathrm{Al}_{2} \mathrm{O}_{3}$ water nanofluid has a better thermal conductivity when compared to $\mathrm{ZnO}$ nanofluids. However, the hybrid nanofluids at all the considered mixture ratios have higher thermal conductivity than both $\mathrm{Al}_{2} \mathrm{O}_{3}$ water nanofluid and $\mathrm{ZnO}$ water nanofluid; this is in agreement with the literature where thermal conductivity of hybrid nanofluids has shown to be higher than that of conventional nanofluids [24].

\section{Effect of temperature on thermal conductivity of $\mathrm{Al}_{2} \mathrm{O}_{3}-\mathrm{ZnO}$ hybrid nanofluid}

Figure $8 \mathrm{a}-\mathrm{c}$ shows the thermal conductivity and temperature relationship for $\mathrm{Al}_{2} \mathrm{O}_{3}-\mathrm{ZnO}$ hybrid nanofluid at 1:2, $1: 1$ and 2:1 $\left(\mathrm{Al}_{2} \mathrm{O}_{3}: \mathrm{ZnO}\right)$ mixture ratios, respectively. We observe that for each mixture ratio, an increase in the suspension temperature enhances the thermal conductivity of the nanofluid. This rate of enhancement with temperature is relatively constant for all mixture ratios considered at all volume concentration consider. This phenomenon is also observed in the base fluid and agrees with the thermal conductivity-temperature relationship proposed in Callaway's model [65]. Within the temperature range considered in this study, thermal conductivity is expected to increase with temperature increase. The highest thermal enhancements observed in the $\mathrm{Al}_{2} \mathrm{O}_{3}-\mathrm{ZnO}$ hybrid nanofluids at $1: 2$, 1:1 and $2: 1\left(\mathrm{Al}_{2} \mathrm{O}_{3}: \mathrm{ZnO}\right)$ mixture ratios were $36 \%, 35 \%$, and $40 \%$, respectively, at volume concentration $1.67 \%$ and $65^{\circ} \mathrm{C}$.

\section{Effect of volume concentration on thermal conductivity of $\mathrm{Al}_{2} \mathrm{O}_{3}-\mathrm{ZnO}$ hybrid nanofluid}

Figure $9 \mathrm{a}-\mathrm{c}$ shows the thermal conductivity volume concentration relationship for $\mathrm{Al}_{2} \mathrm{O}_{3}-\mathrm{ZnO}$ hybrid nanofluid at 1:2, 1:1 and 2:1 $\left(\mathrm{Al}_{2} \mathrm{O}_{3}: \mathrm{ZnO}\right)$ mixture ratios, respectively. We observe that for each mixture ratio, the increase in volume concentration of the nanofluid increases the thermal conductivity of the nanofluids.

Within the range of volume, concentration investigated the maximum thermal conductivity achieved for $\mathrm{Al}_{2} \mathrm{O}_{3}-\mathrm{ZnO}$ hybrid nanofluids at 1:2,1:1 and 2:1 $\left(\mathrm{Al}_{2} \mathrm{O}_{3}: \mathrm{ZnO}\right)$ mixture ratios was $36 \%, 35 \%$ and $40 \%$, respectively, at volume concentration $1.67 \%$ and $65^{\circ} \mathrm{C} . \mathrm{Al}_{2} \mathrm{O}_{3}-\mathrm{ZnO}$ hybrid nanofluid at $0.33 \%$ volume concentration provided the least thermal conductivity within the considered range. 
Fig. 8 Effect of temperature on thermal conductivity of $\mathrm{Al}_{2} \mathrm{O}_{3}-$ $\mathrm{ZnO}$ nanofluids at different mixture ratios a 1:2, b 1:1 and $\mathbf{c}$ $2: 1\left(\mathrm{Al}_{2} \mathrm{O}_{3}: \mathrm{ZnO}\right)$
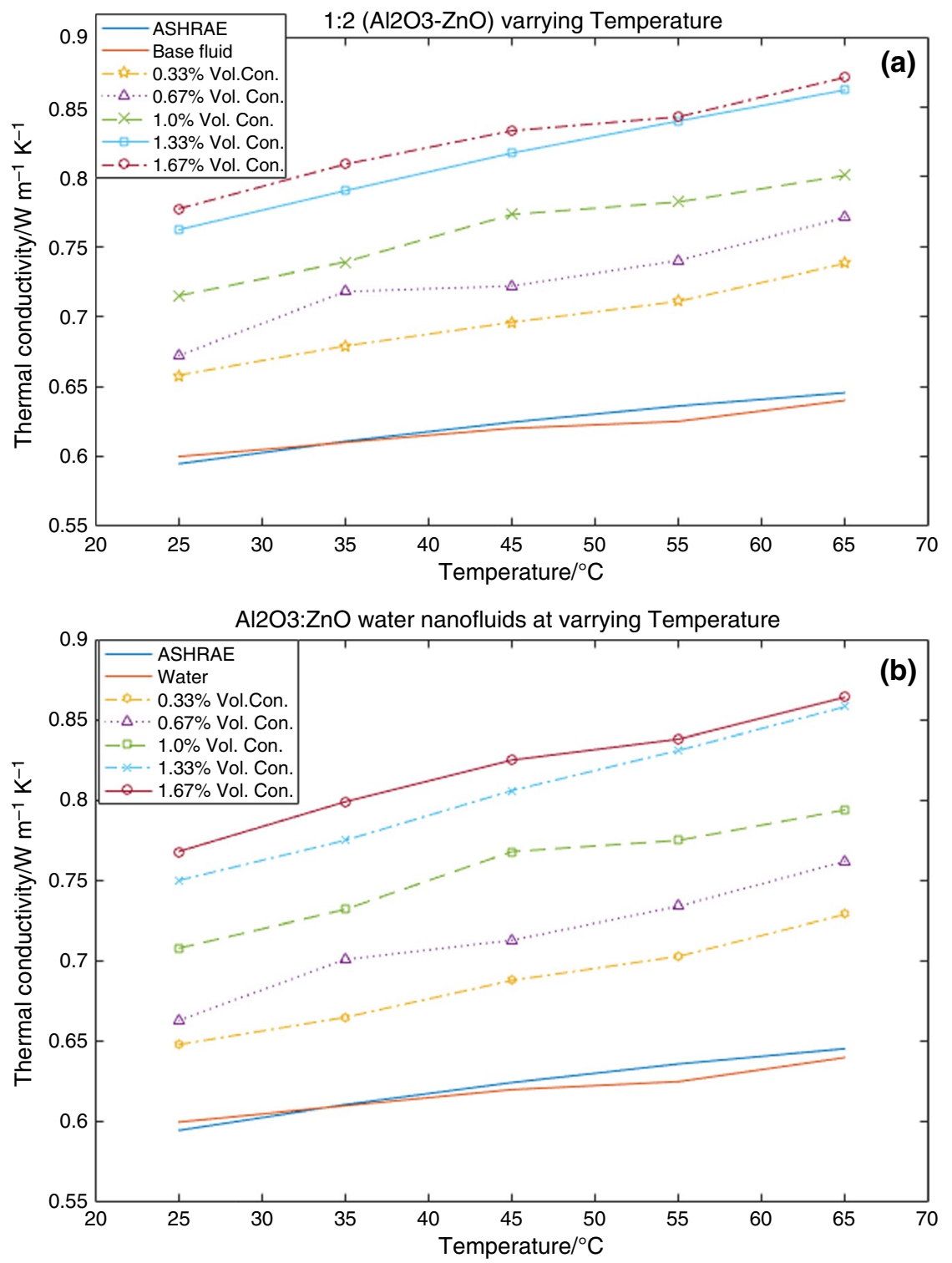

Thermal conductivity of 2:1 (Al2O3- $\mathrm{ZnO}$ ) varrying Temperature

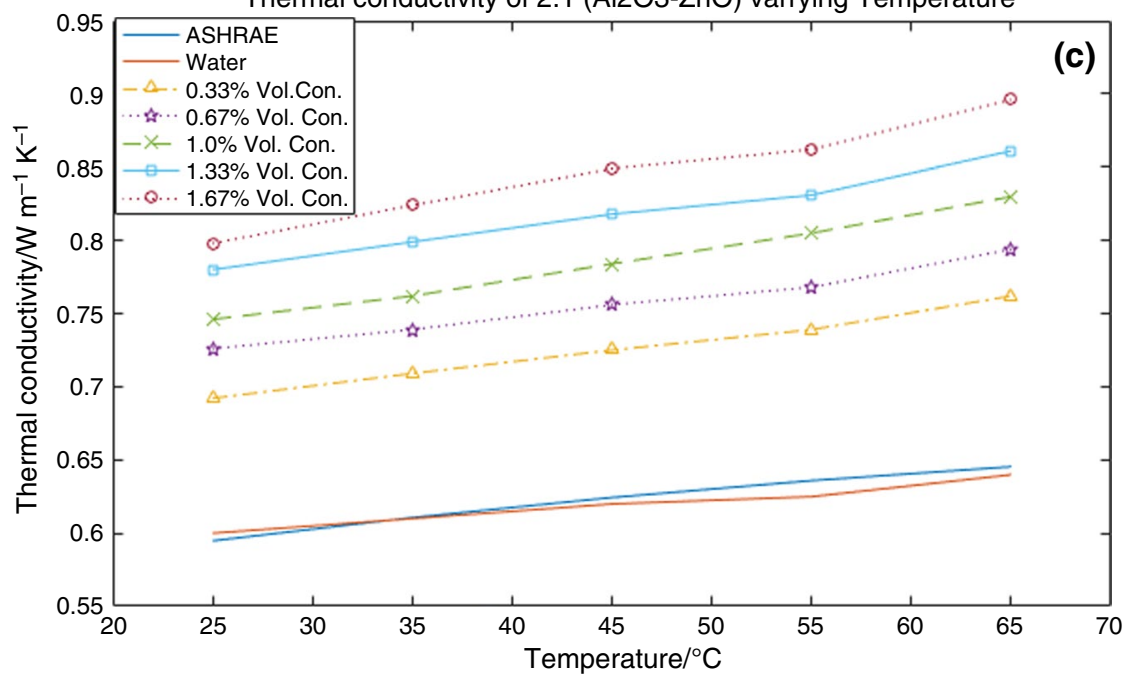


Fig. 9 Effect of volume concentration on thermal conductivity of $\mathrm{Al}_{2} \mathrm{O}_{3}-\mathrm{ZnO}$ nanofluids at different mixture ratios a $1: 2, \mathbf{b}$ $1: 1$ and $\mathbf{c} 2: 1\left(\mathrm{Al}_{2} \mathrm{O}_{3}: \mathrm{ZnO}\right)$
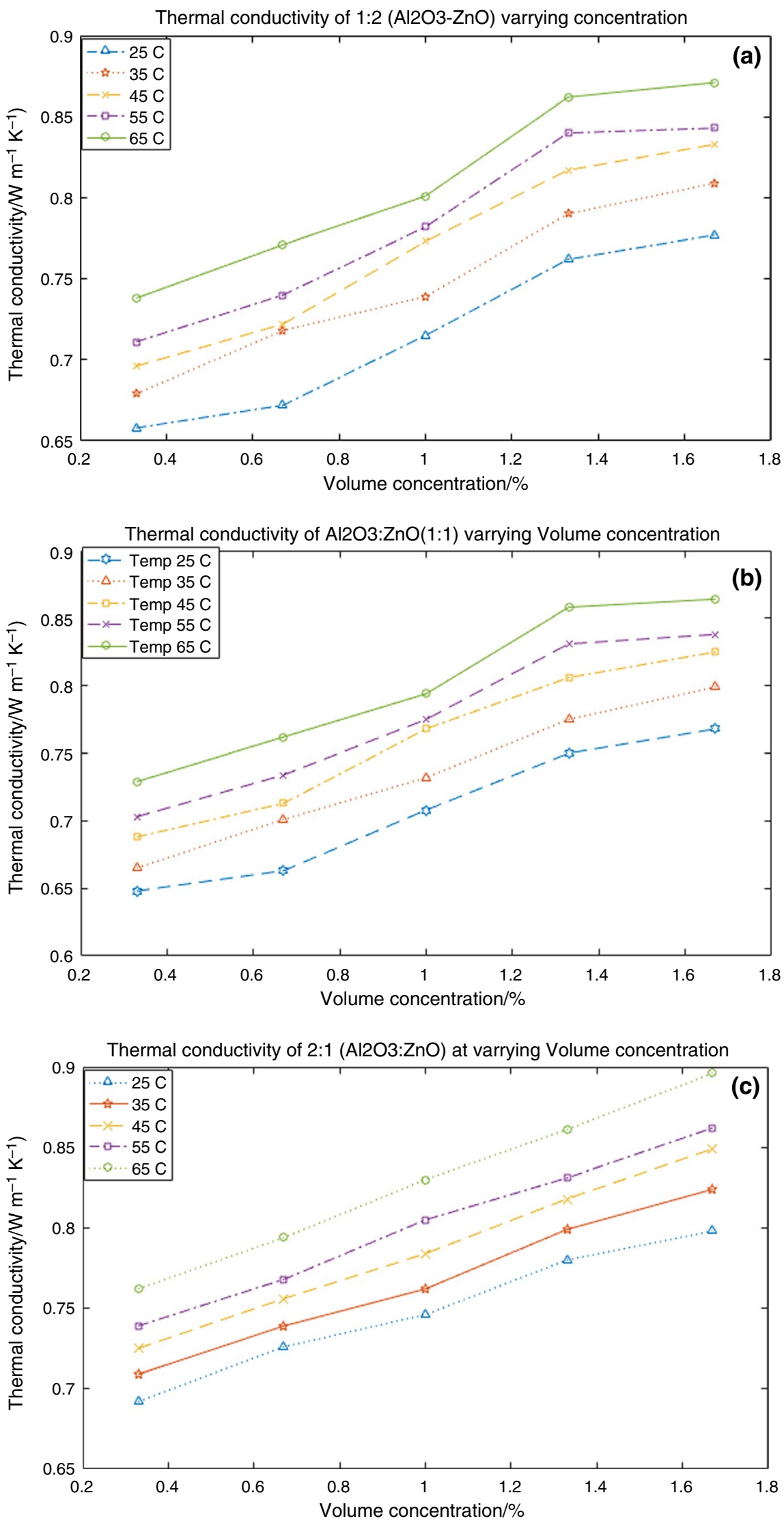
Fig. 10 Effect of particle mixture ratio on thermal conductivity of $\mathrm{Al}_{2} \mathrm{O}_{3}-\mathrm{ZnO}$ nanofluids at $\mathbf{a} 25^{\circ} \mathrm{C}$ and (b) $1 \%$ volume concentration

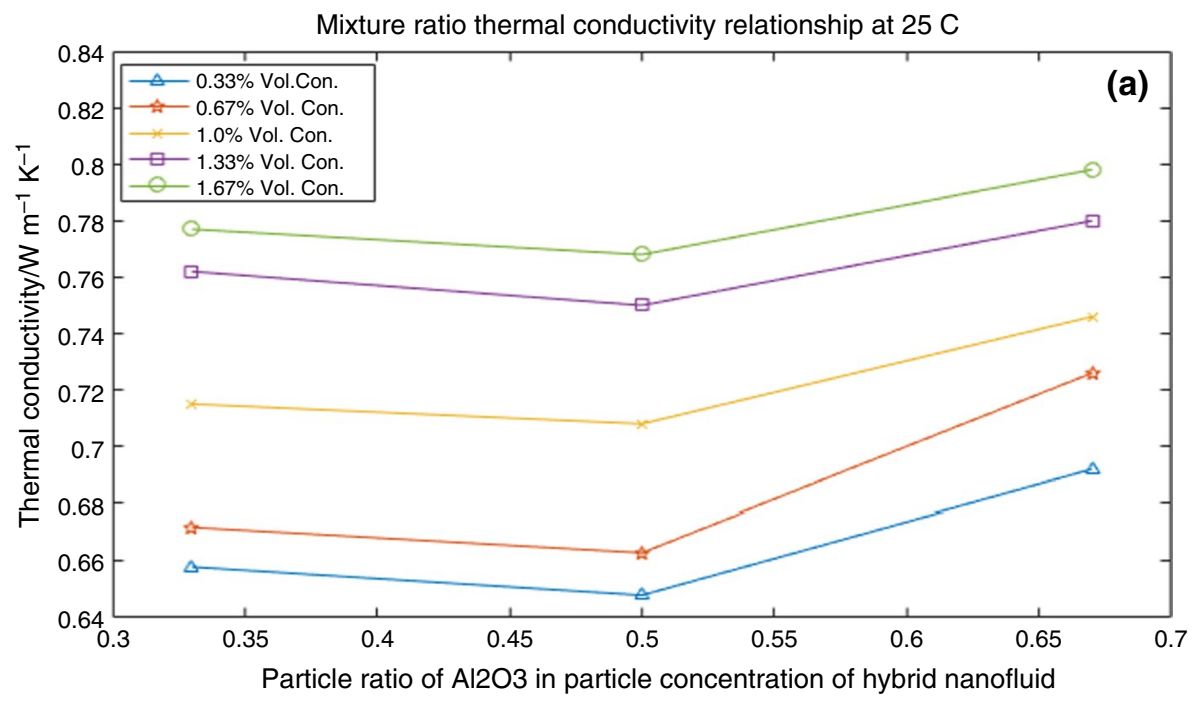

Thermal conductivity particle ratio relationship at $1 \%$ Vol. Conc.

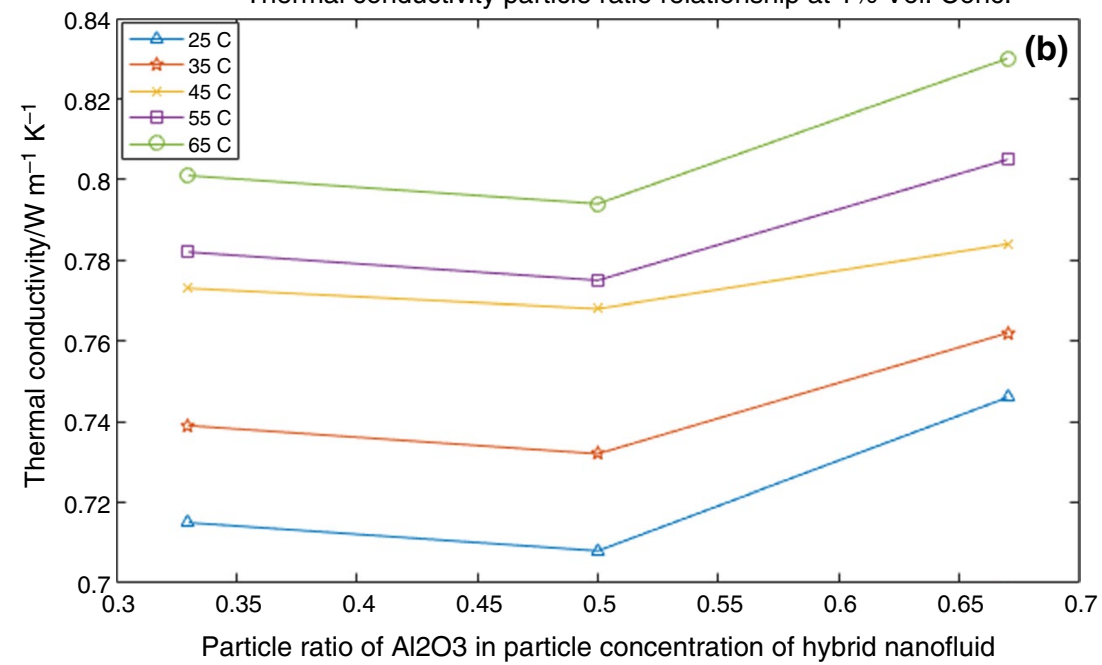

\section{Effect of mixture ratio on thermal conductivity of $\mathrm{Al}_{2} \mathrm{O}_{3}-\mathrm{ZnO}$ hybrid nanofluid}

Figure 10 shows the thermal conductivity of $\mathrm{Al}_{2} \mathrm{O}_{3}-\mathrm{ZnO}$ hybrid nanofluid as the particle ratio of $\mathrm{Al}_{2} \mathrm{O}_{3}$ is increased from one-third to half and ultimately to two-third of the particle concentration of the hybrid. Figure 10a, b shows the effect of the particle mixture ratio at a temperature of $25^{\circ} \mathrm{C}$ and a volume concentration of $1.0 \%$, respectively. It is observed that the particle mixture ratio and thermal conductivity relation is nonlinear. As the ratio $\mathrm{Al}_{2} \mathrm{O}_{3}$ particle is increased, a "deeping effect" is noticed when the mixture ratio is 0.5 , and the maximum thermal conductivity enhancement is observed when $\mathrm{Al}_{2} \mathrm{O}_{3}$ constitutes 0.67 of particle concentration.

The "deeping" effect was first observed by Hamid et al. [48] in $\mathrm{TiO}_{2}-\mathrm{SiO}_{2}$ hybrid nanofluid. According to Hamid et al. [48], the "deeping" effect might be due to the size of the particles. Hamid et al. [48] proposed that the amount of the smaller particles present in the mixture and the unique arrangement of the nanoparticles may explain this effect. In this study, the $\mathrm{Al}_{2} \mathrm{O}_{3}$ average nanoparticles size is $29 \mathrm{~nm}$, and the $\mathrm{ZnO}$ nanoparticle has an average particle size of $70 \mathrm{~nm}$. Therefore, Hamid et al. [48] observation resonates with the $\mathrm{Al}_{2} \mathrm{O}_{3}-\mathrm{ZnO}$ hybrid nanofluid investigation; when the $\mathrm{Al}_{2} \mathrm{O}_{3}-\mathrm{ZnO}$ hybrid is at 1:1 mixture ratio, the nanofluid has the lowest amount of particles. However, when the $\mathrm{Al}_{2} \mathrm{O}_{3}-\mathrm{ZnO}$ hybrid nanofluid has a mixture ratio of 2:1 the fluid has the highest amount of particles.

\section{Correlation model}

A correlation equation was developed using the experimental data from thermal conductivity measurements of the hybrid nanofluid. Unlike previous models discussed in Table 3, this model accounts for the effect of the mixture 
Table 4 Values of coefficient in Eq. (16)

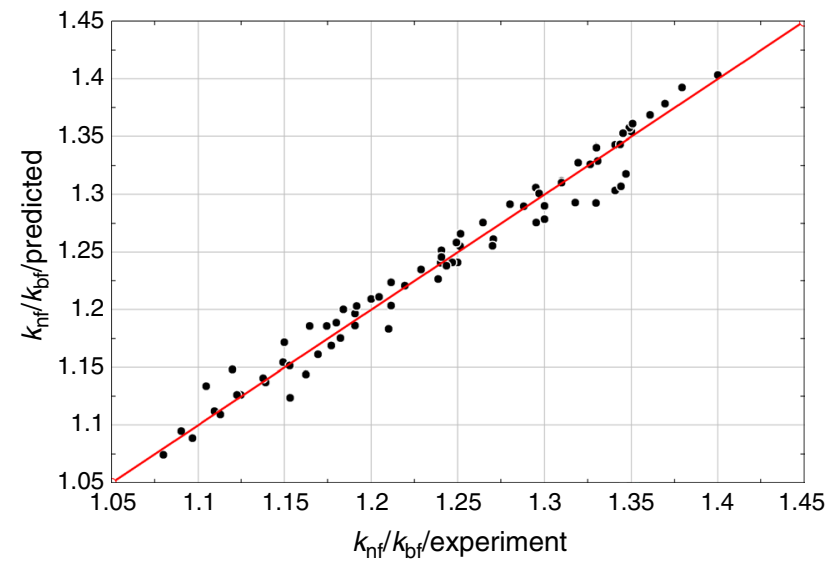

Fig. 11 Correlation model experimental $k_{\text {eff }}$ versus predicted $k_{\text {eff }}$

ratio on the thermal conductivity of the hybrid nanofluids. Unlike most studies in the literature where a power multiplicative function is used, this study uses a polynomial additive model as it would better account for the "deeping" effect witnessed from the experimental results. The correlation model is presented in Eq. (16).

$\frac{k_{\mathrm{nf}}}{k_{\mathrm{bf}}}=a_{0}+a_{1} T+a_{2} T^{2}+a_{3} R+a_{4} R^{2}+a_{5} \varphi+a_{6} \varphi^{2}$

where $T$ represents temperature, $\varphi$ represents volume concentration and $R$ represents the ratio of $\mathrm{Al}_{2} \mathrm{O}_{3}$ in nanoparticle concentration.

The equation approximates the thermal conductivity of water-based $\mathrm{Al}_{2} \mathrm{O}_{3}-\mathrm{ZnO}$ hybrid nanofluids for temperatures ranging between 25 and $70{ }^{\circ} \mathrm{C}$ and volume concentration below $2 \%$. Table 4 shows the value of the constants in Eq. (16), determined by multivariate regression.

The model was statistically validated by determining the RMS value and the $R^{2}$ value. The $R^{2}$ value of the regression correlation presented in Eq. (16) is 0.9718 , with an RMS value of 0.014. Also, Fig. 11 shows the forecasted values obtained from the regression correlation and the recorded experimental value for thermal conductivity are in good agreement.
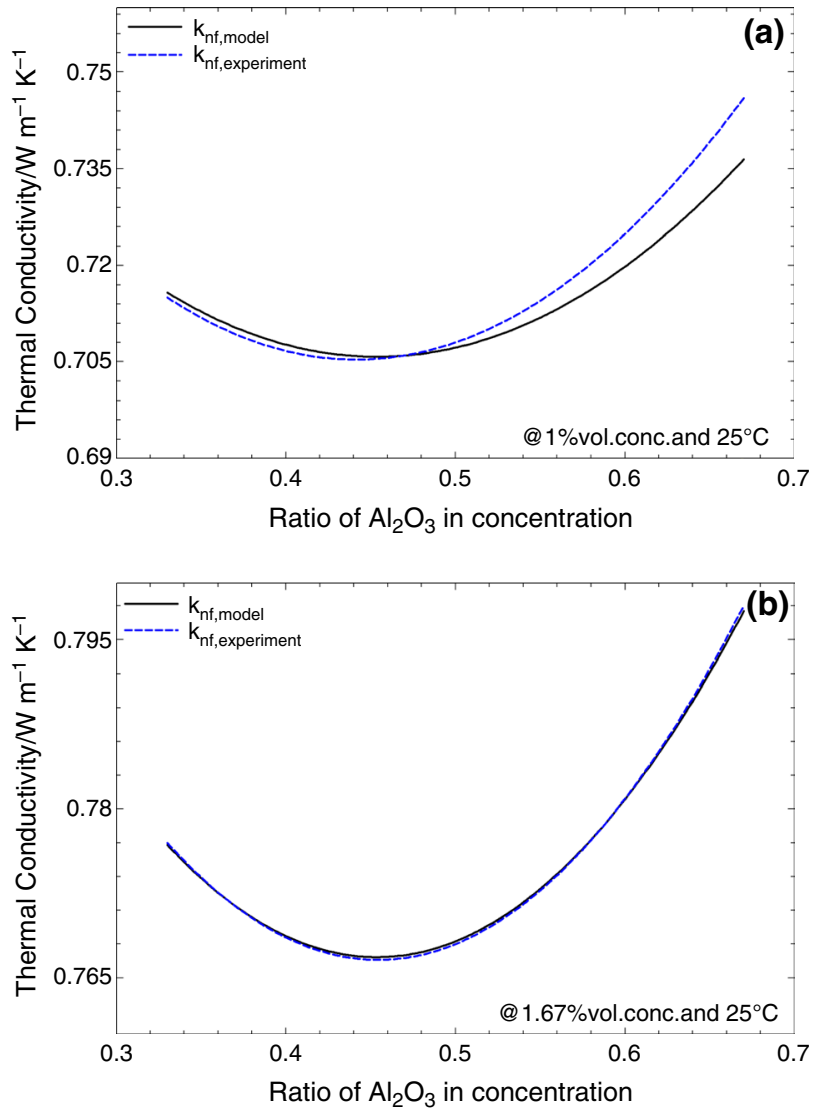

Fig. 12 Comparison between correlations predicted $k_{\mathrm{nf}}$ and experimental $k_{\mathrm{nf}}$ at varying mixture ratios a $1 \%$ volumetric concentration and $\mathbf{b} 1.67 \%$ volumetric concentration

Table 5 Training parameters for ANFIS model

\begin{tabular}{ll}
\hline Parameters & Values \\
\hline No of Membership function & 333 \\
Membership function type & Trimf \\
Membership function type (output) & Constant
\end{tabular}

Table 6 Performance values for estimating thermal conductivity

\begin{tabular}{llll}
\hline & $R^{2}$ & RMSE & SSE \\
\hline $\begin{array}{l}\text { Training and } \\
\text { testing }\end{array}$ & 0.9902 & 0.0010036 & 0.00058418 \\
Testing & 0.9946 & 0.0049 & 0.0049 \\
\hline
\end{tabular}

Figure 12 compares the proposed regression model to experimental data for varying mixture ratio. It is observed that the model is in good agreement with experimental data. The mixture ratio of the hybrid nanofluid is not accounted for in all proposed models and therefore cannot identify the behaviour of $\mathrm{Al}_{2} \mathrm{O}_{3}-\mathrm{ZnO}$ hybrid nanofluids at different 
mixture ratios. Figure 12a, $\mathrm{b}$ shows a comparison between the model value and experimental value at constant temperature and volume concentration of $1.0 \%$ and $1.67 \%$, respectively.

\section{Intelligent prediction models}

In this section, the results from the soft computing tools (ANFIS and ANN) are presented and discussed. The goal is to estimate the most efficient model for accurately predicting the experimental values of the thermal conductivity of the hybrid nanofluid.

\section{ANFIS approach}

The performance of the ANFIS model is assessed using the $R^{2}$, RMSE and SSE values. The training parameters and results are given in Tables 5 and 6, respectively.

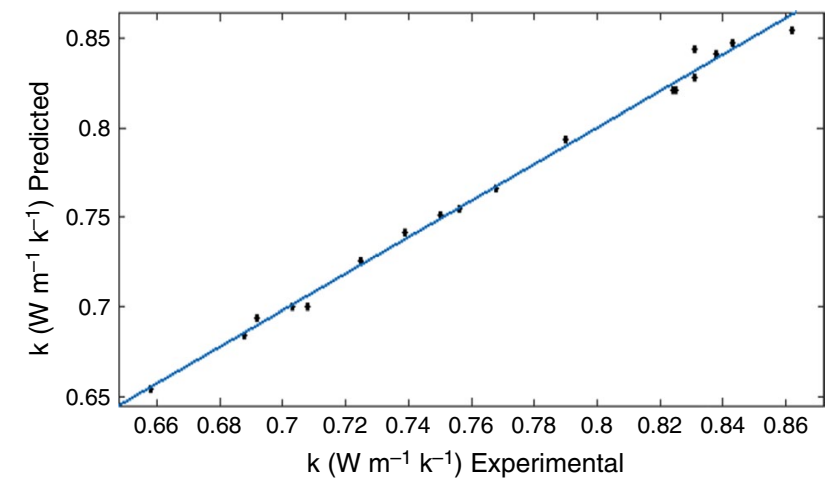

Fig. 13 ANFIS scatter plots of predicted versus experimental result of thermal conductivity (testing dataset)
Table 5 shows the number of membership functions applied in fuzzing the output. The triangular membership function was applied; triangular membership function is the simplest shaped membership function [63]. The experimental values for thermal conductivity very much agree with the predicted values obtained from the ANFIS model based on the statistical analysis shown in Fig. 13. It can be observed that the prediction is almost exact with the experimental result. However, there are some negligible deviations from the perfect experimental data. The marginal deviation of the predicted and experimental values of the thermal conductivity is calculated as:

$\left[\% \mathrm{MOD}=\frac{k_{\text {exp }}-k_{\text {pred }}}{k_{\text {exp }}}\right] \times 100$

The margin of deviation (MOD) of the predicted values using the ANFIS computation is within $\pm 1.4 \%$ range.

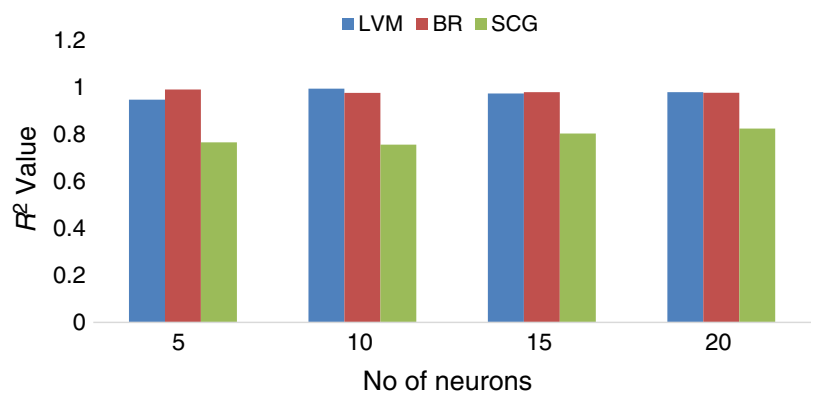

Fig. 14 Performance of training algorithms for different neurons in the hidden layer
Table 7 ANN model optimised with LVM, BR and SCG algorithms

\begin{tabular}{|c|c|c|c|c|c|c|}
\hline \multirow[t]{2}{*}{ No of neurons } & \multicolumn{3}{|c|}{ Training } & \multicolumn{3}{|l|}{ Testing } \\
\hline & $\overline{R^{2}}$ & RMSE & SSE & $\overline{\mathrm{R}^{2}}$ & RMSE & \\
\hline \multicolumn{7}{|l|}{$L V M$} \\
\hline 5 & 0.9458 & 0.0002032 & $1.65 \mathrm{E}-06$ & 0.9791 & 0.0064 & 0.0006515 \\
\hline 10 & 0.9925 & $8.359 \mathrm{E}-05$ & $2.795 \mathrm{E}-07$ & 0.9909 & 0.0045 & 0.0003187 \\
\hline 15 & 0.9718 & 0.0001488 & $8.855 \mathrm{E}-07$ & 0.9344 & 0.0117 & 0.0022 \\
\hline 20 & 0.9772 & 0.0001484 & $8.803 \mathrm{E}-07$ & 0.973 & 0.0074 & 0.0008798 \\
\hline \multicolumn{7}{|l|}{$B R$} \\
\hline 5 & 0.9887 & 0.0001004 & $4.034 \mathrm{E}-07$ & 0.9928 & 0.0038 & 0.0002336 \\
\hline 10 & 0.9745 & 0.0001464 & $8.57 \mathrm{E}-07$ & 0.9922 & 0.0038 & 0.0002347 \\
\hline 15 & 0.9772 & 0.0001357 & $7.365 \mathrm{E}-07$ & 0.9896 & 0.0042 & 0.0002798 \\
\hline 20 & 0.9747 & 0.0001448 & $8.384 \mathrm{E}-07$ & 0.9912 & 0.0042 & 0.000279 \\
\hline \multicolumn{7}{|l|}{$S C G$} \\
\hline 5 & 0.7645 & 0.0004945 & $9.782 \mathrm{E}-06$ & 0.5084 & 0.0208 & 0.0069 \\
\hline 10 & 0.7544 & 0.0004212 & $7.096 \mathrm{E}-06$ & 0.7556 & 0.02 & 0.0064 \\
\hline 15 & 0.8019 & 0.0005099 & $1.04 \mathrm{E}-05$ & 0.5481 & 0.0279 & 0.0125 \\
\hline 20 & 0.8229 & 0.0004634 & $8.59 \mathrm{E}-06$ & 0.7957 & 0.0326 & 0.0171 \\
\hline
\end{tabular}


Table 8 Testing data for three predictive models

\begin{tabular}{llll}
\hline Experiment & ANFIS model & Correlation model & ANN model \\
\hline 0.708 & 0.699846 & 0.708876 & 0.701137 \\
0.75 & 0.751563 & 0.738888 & 0.742343 \\
0.768 & 0.766251 & 0.768694 & 0.772545 \\
0.688 & 0.683931 & 0.685724 & 0.689208 \\
0.825 & 0.820865 & 0.826188 & 0.82942 \\
0.703 & 0.699873 & 0.698757 & 0.694243 \\
0.831 & 0.827905 & 0.811377 & 0.827536 \\
0.838 & 0.841115 & 0.847435 & 0.845993 \\
0.658 & 0.654292 & 0.645467 & 0.646128 \\
0.739 & 0.741426 & 0.74582 & 0.752335 \\
0.79 & 0.793719 & 0.78088 & 0.7969 \\
0.843 & 0.847486 & 0.869087 & 0.846427 \\
0.692 & 0.693937 & 0.68824 & 0.686875 \\
0.824 & 0.82039 & 0.828387 & 0.821023 \\
0.725 & 0.725849 & 0.723599 & 0.722371 \\
0.756 & 0.754535 & 0.757789 & 0.755527 \\
0.831 & 0.843253 & 0.837233 & 0.84616 \\
0.862 & 0.854264 & 0.870174 & 0.867919 \\
$R^{2}$ & 0.9946 & 0.9826 & 0.9919 \\
\hline
\end{tabular}

Table 6 shows the ANFIS to have an $R^{2}$ value of 0.9946 . This value is a higher value than the $R^{2}$ value of the proposed correlation model. Therefore, the ANFIS model is a better predictive model for the hybrid nanofluid than the proposed correlation model.

\section{ANN approach}

Various types of ANN models have been analysed, and the test results are shown in Table 7. Figure 14 shows the performance of the ANN models for each algorithm and an increasing number of neurons with one hidden layer. It is shown that the least efficient algorithm is the SCG. The LVM and BR have almost the same prediction accuracy. The reason for this is that they give a better generalisation for noisy and small datasets. The BR algorithm minimises squared errors and masses, which gives a more generalised and efficient model. The most accurate model is the BR algorithm with five neurons in the hidden layer, and an $R^{2}$ value of 0.9928; increasing the number of neurons in the hidden layer did not appear to improve model's predictions. When the SCG algorithm is applied to the ANN, increasing the number of neurons in the hidden layer tends to increase the accuracy of the ANN. However, this is not observable in the both LVM- and BR-optimised models.

The ANN, ANFIS and correlation models are compared in terms of accuracy in prediction of the experimental thermal conductivity values. This comparison is made for all the test datasets, which were not used in the training phase of the neural network models. The ANN architecture of LVM algorithm with 10 neurons is chosen for this comparative analysis as it is the best model obtained from the ANN design. Table 8 shows that the ANFIS model has the best ability to accurately predict the thermal conductivity of the experimentally observed $\mathrm{Al}_{2} \mathrm{O}_{3}-\mathrm{ZnO}$ hybrid nanofluid. Table 8 also shows that while the ANFIS prediction model is most accurate in predicting thermal conductivity while the correlation model is the least efficient in predicting the thermal conductivity especially at higher values.

\section{Conclusions}

An experimental investigation on the thermal conductivity of $\mathrm{Al}_{2} \mathrm{O}_{3}-\mathrm{ZnO}$ water hybrid nanofluids at three different mixture ratios and at a volume concentration of $0.33 \%$, $0.67 \% 1.00 \%, 1.33 \%$ and $1.67 \%$ is studied. The experimentally measured results for the hybrid nanofluids are presented and the following significant findings:

- The thermal conductivity of the hybrid nanofluids increases with an increase in volume concentration and also increases as temperature increases within the considered range.

- The maximum thermal conductivity enhancement achieved for $\mathrm{Al}_{2} \mathrm{O}_{3}-\mathrm{ZnO}$ hybrid nanofluids with 1:2, 1:1 and 2:1 $\left(\mathrm{Al}_{2} \mathrm{O}_{3}: \mathrm{ZnO}\right)$ mixture ratios was $36 \%, 35 \%$ and $40 \%$, respectively, at volume concentration $1.67 \%$ and $65^{\circ} \mathrm{C}$.

- $\mathrm{Al}_{2} \mathrm{O}_{3}-\mathrm{ZnO}$ nanofluids at a 1:1 mixture ratio present the least value for thermal conductivity when compared to 2:1 and 1:2 mixture ratio at all volume concentrations and temperature ranges considered.

- A "deeping" effect is observed for thermal conductivity when the hybrid mixture is at a ratio of 1:1. We attribute this effect to be as a result of the total number of particles within the nanofluid and difference in average particle size between the $\mathrm{Al}_{2} \mathrm{O}_{3}$ and $\mathrm{ZnO}$ nanoparticles.

- The thermal conductivity models used in the study significantly deviated from experiment results and could not account for the "deeping" effect observed at the 1:1 mixture ratio.

- The correlation model proposed in this study was in good agreement with measured data and accounted for the effect of the mixture ratio on the thermal conductivity of the hybrid nanofluid with an $R^{2}$ value of 0.9826 .

- ANN model showed almost perfect prediction with an $R^{2}$ value of 0.9928 . The BR algorithm gave this best fit.

- The ANFIS model gave the best prediction accuracy for the experimentally obtained thermal conductivity values with an $R^{2}$ value of 0.9946 . 
Acknowledgements Open Access funding provided by the Qatar National Library. Open Access funding provided by the Qatar National Library.

Open Access This article is licensed under a Creative Commons Attribution 4.0 International License, which permits use, sharing, adaptation, distribution and reproduction in any medium or format, as long as you give appropriate credit to the original author(s) and the source, provide a link to the Creative Commons licence, and indicate if changes were made. The images or other third party material in this article are included in the article's Creative Commons licence, unless indicated otherwise in a credit line to the material. If material is not included in the article's Creative Commons licence and your intended use is not permitted by statutory regulation or exceeds the permitted use, you will need to obtain permission directly from the copyright holder. To view a copy of this licence, visit http://creativecommons.org/licenses/by/4.0/.

\section{References}

1. Abdullah MIHC, Abdollah MF Bin, Amiruddin H, Tamaldin N, Nuri NRM. Optimization of tribological performance of hBN/ $\mathrm{Al}_{2} \mathrm{O}_{3}$ nanoparticles as engine oil additives. Procedia Eng. 2013;68:313-9.

2. Qiu L, Zhu N, Feng Y, Michaelides EE, Żyła G, Jing D, Zhang X, Norris PM, Markides CN, Mahian O. A review of recent advances in thermophysical properties at the nanoscale: from solid state to colloids. Phys Rep. 2020;843:1-81.

3. Pourzad A, Sobhi HR, Behbahani M, Esrafili A, Kalantary RR, Kermani M. Efficient visible light-induced photocatalytic removal of paraquat using $\mathrm{N}$-doped $\mathrm{TiO}_{2} @ \mathrm{SiO}_{2} @ \mathrm{Fe}_{3} \mathrm{O}_{4}$ nanocomposite. J Mol Liq. 2019;299:112167.

4. Pourrajab R, Noghrehabadi A, Behbahani M, Hajidavalloo E. An efficient enhancement in thermal conductivity of water-based hybrid nanofluid containing MWCNTs-COOH and Ag nanoparticles: experimental study. J Therm Anal Calorim. 2020. https:// doi.org/10.1007/s10973-020-09300-y.

5. Rohsenow WM, Hartnett JP, Cho YI. Handbook of heat transfer. New York: McGraw-Hill; 1998.

6. Das SK, Choi SUS, Yu W, Pradeep T. Nanofluids: science and technology. Hoboken: Wiley; 2007.

7. Choi SUS, Eastman JA. Enhancing thermal conductivity of fluids with nanoparticles. Am. Soc Mech Eng. Fluids Eng Div FED. 1995;231:99-105.

8. Bulut E, Özacar M. Rapid, facile synthesis of silver nanostructure using hydrolyzable tannin. Ind Eng Chem Res. 2009;48(12):5686-90.

9. Lin S, Chen Y, Tan X, Song F, Pun EYB, He Z, Pu J. Catalytic performance of $\mathrm{Fe}_{3} \mathrm{O}_{4}$ nanoparticles for cyclocondensation synthesis of thiacrown ethers. Mater Res Express. 2015;2(1):015010.

10. Gan Arıkan E, Glu A, Gazi M. Experimental performance analysis of flat plate solar collectors using different nanofluids. Sustainability. 2018;10(6):1794

11. Ahmadi MH, Mirlohi A, Alhuyi Nazari M, Ghasempour R. A review of thermal conductivity of various nanofluids. J Mol Liq. 2018;265:181-8

12. Chen Z, Tozaki K, Nishikawa K. Development of thermal conductivity measurement for fluids which is convenient and effective for samples near the critical point. Jpn J Appl Phys. 1999;38(1A):L92.

13. Simpson S, Schelfhout A, Golden C, Vafaei S. Nanofluid thermal conductivity and effective parameters. Appl Sci. 2018;9(1):87.

14. Bashirnezhad K, Rashidi MM, Yang Z, Bazri S, Yan WM. A comprehensive review of last experimental studies on thermal conductivity of nanofluids. J Therm Anal Calorim. 2015;122(2):863-84.
15. Kumar N, Sonawane SS, Sonawane SH. Experimental study of thermal conductivity, heat transfer and friction factor of $\mathrm{Al}_{2} \mathrm{O}_{3}$ based nanofluid. Int Commun Heat Mass Transf. 2018;90:1-10.

16. Izadkhah MS, Erfan-Niya H, Heris SZ. Influence of graphene oxide nanosheets on the stability and thermal conductivity of nanofluids: insights from molecular dynamics simulations. J Therm Anal Calorim. 2019;135(1):581-95.

17. Agarwal R, Verma K, Agrawal NK, Duchaniya RK, Singh R. Synthesis, characterization, thermal conductivity and sensitivity of CuO nanofluids. Appl Therm Eng. 2016;102:1024-36.

18. Hemmat Esfe M, Saedodin S, Mahian O, Wongwises S. Thermal conductivity of $\mathrm{Al}_{2} \mathrm{O}_{3}$ /water nanofluids. J Therm Anal Calorim. 2014;117(2):675-81.

19. Akilu S, Baheta AT, Minea AA, Sharma KV. Rheology and thermal conductivity of non-porous silica $\left(\mathrm{SiO}_{2}\right)$ in viscous glycerol and ethylene glycol based nanofluids. Int Commun Heat Mass Transf. 2017;88:245-53.

20. Das S, Giri A, Samanta S, Kanagaraj S. Role of graphene nanofluids on heat transfer enhancement in thermosyphon. J Sci Adv Mater Devices. 2019;4(1):163-9.

21. Gangadevi R, Vinayagam BK. Experimental determination of thermal conductivity and viscosity of different nanofluids and its effect on a hybrid solar collector. J Therm Anal Calorim. 2019;136(1):199-209.

22. Toghraie D, Chaharsoghi VA, Afrand M. Measurement of thermal conductivity of $\mathrm{ZnO}-\mathrm{TiO}_{2} / \mathrm{EG}$ hybrid nanofluid. J Therm Anal Calorim. 2016;125(1):527-35.

23. Esfahani NN, Toghraie D, Afrand M. A new correlation for predicting the thermal conductivity of $\mathrm{ZnO}-\mathrm{Ag}(50 \%-50 \%) /$ water hybrid nanofluid: an experimental study. Powder Technol. 2018;323(2018):367-73.

24. Sajid MU, Ali HM. Thermal conductivity of hybrid nanofluids: a critical review. Int J Heat Mass Transf. 2018;126:211-34.

25. Esfe MH, Saedodin S, Wongwises S, Toghraie D. An experimental study on the effect of diameter on thermal conductivity and dynamic viscosity of Fe/water nanofluids. J Therm Anal Calorim. 2015;119(3):1817-24.

26. Chevalier J, Tillement O, Ayela F. Rheological properties of nanofluids flowing through microchannels. Appl Phys Lett. 2007;91(23):233103.

27. Hong J, Kim D. Effects of aggregation on the thermal conductivity of alumina/water nanofluids. Thermochim Acta. 2012;542:28-32.

28. Prasher R, Evans W, Meakin P, Fish J, Phelan P, Keblinski P. Effect of aggregation on thermal conduction in colloidal nanofluids. Appl Phys Lett. 2006;89(14):143119.

29. Parameshwaran R, Kalaiselvam S. Effect of aggregation on thermal conductivity and heat transfer in hybrid nanocomposite phase change colloidal suspensions. Appl Phys Lett. 2013;103(19):193113.

30. Gerardi C, Cory D, Buongiorno J, Hu LW, McKrell T. Nuclear magnetic resonance-based study of ordered layering on the surface of alumina nanoparticles in water. Appl Phys Lett. 2009;65(25):253104.

31. Liang Z, Tsai HL. Thermal conductivity of interfacial layers in nanofluids. Phys Rev E Stat Nonlinear Soft Matter Phys. 2011;83(4):041602.

32. Yu W, Choi SUS. The role of interfacial layers in the enhanced thermal conductivity of nanofluids: a renovated HamiltonCrosser model. J Nanopart Res. 2004;6(4):355-61.

33. Maxwell JC. A treatise on electricity and magnetism, vol. 2. London: Clarendon Press; 1881.

34. Xue QZ. Model for effective thermal conductivity of nanofluids. Phys Lett Sect A Gen At Solid State Phys. 2003;307(5-6):313-7. 
35. Xie H, Fujii M, Zhang X. Effect of interfacial nanolayer on the effective thermal conductivity of nanoparticle-fluid mixture. Int J Heat Mass Transf. 2005;48(14):2926-32.

36. Koo J, Kleinstreuer C. A new thermal conductivity model for nanofluids. J Nanopart Res. 2004;6(6):577-88.

37. Aybar H, Sharifpur M, Azizian MR, Mehrabi M, Meyer JP. A review of thermal conductivity models for nanofluids. Heat Transf Eng. 2015;36(13):1085-110.

38. Zadkhast M, Toghraie D, Karimipour A. Developing a new correlation to estimate the thermal conductivity of MWCNT-CuO/ water hybrid nanofluid via an experimental investigation. J Therm Anal Calorim. 2017;129(2):859-67.

39. Hemmat Esfe M, Kiannejad Amiri M, Alirezaie A. Thermal conductivity of a hybrid nanofluid: a new economic strategy and model. J Therm Anal Calorim. 2018;134(2):1113-22.

40. Jang SP, Choi SUS. Role of Brownian motion in the enhanced thermal conductivity of nanofluids. Appl Phys Lett. 2004;84(21):4316-8.

41. Moosavi M, Firoozi Rad K, Daneshvar A. A comparative study in the prediction of thermal conductivity enhancement of nanofluids using ANN-MLP, ANN-RBF, ANFIS, and GMDH methods. J Iran Chem Soc. 2019;16(2019):2629-37.

42. Li L, Zhai Y, Jin Y, Wang J, Wang H, Ma M. Stability, thermal performance and artificial neural network modeling of viscosity and thermal conductivity of $\mathrm{Al}_{2} \mathrm{O}_{3}$-ethylene glycol nanofluids. Powder Technol. 2020;363(2020):360-8.

43. Razavi R, Sabaghmoghadam A, Bemani A, Baghban A, Chau KW, Salwana E. Application of ANFIS and LSSVM strategies for estimating thermal conductivity enhancement of metal and metal oxide based nanofluids. Eng Appl Comput Fluid Mech. 2019;13(1):560-78.

44. Ma M, Zhai Y, Wang J, Yao P, Wang H. Statistical image analysis of uniformity of hybrid nanofluids and prediction models of thermophysical parameters based on artificial neural network (ANN). Powder Technol. 2020;362(2020):257-66.

45. Ahmadi MH, Baghban A, Sadeghzadeh M, Hadipoor M, Ghazvini $\mathrm{M}$. Evolving connectionist approaches to compute thermal conductivity of $\mathrm{TiO}_{2}$ /water nanofluid. Phys A Stat Mech Appl. 2020;540:122489.

46. Peng Y, Parsian A, Khodadadi H, Akbari M, Ghani K, Goodarzi M, Bach QV. Develop optimal network topology of artificial neural network (AONN) to predict the hybrid nanofluids thermal conductivity according to the empirical data of $\mathrm{Al}_{2} \mathrm{O}_{3}-\mathrm{Cu}$ nanoparticles dispersed in ethylene glycol. Phys A Stat Mech Appl. 2020;2020:124015.

47. Alarifi IM, Nguyen HM, Bakhtiyari AN, Asadi A. Feasibility of ANFIS-PSO and ANFIS-GA models in predicting thermophysical properties of $\mathrm{Al}_{2} \mathrm{O}_{3}$-MWCNT/oil hybrid nanofluid. Materials (Basel). 2019;12(21):3628.

48. Hamid KA, Azmi WH, Nabil MF, Mamat R. Experimental investigation of nanoparticle mixture ratios on $\mathrm{TiO}_{2}-\mathrm{SiO}_{2}$ nanofluids heat transfer performance under turbulent flow. Int J Heat Mass Transf. 2018;118:617-27.

49. Hassan MI, Alzarooni IA, Shatilla Y. The effect of water-based nanofluid incorporating $\mathrm{Al}_{2} \mathrm{O}_{3}$ nanoparticles on heat pipe performance. Energy Procedia. 2015;75:3201-6.
50. Kanchana C, Zhao Y, Siddheshwar PG. A comparative study of individual influences of suspended multiwalled carbon nanotubes and alumina nanoparticles on Rayleigh-Bénard convection in water. Phys Fluids. 2018;30(8):084101.

51. Wole-Osho I, Okonkwo EC, Kavaz D, Abbasoglu S. An experimental investigation into the effect of particle mixture ratio on specific heat capacity and dynamic viscosity of $\mathrm{Al}_{2} \mathrm{O}_{3}-\mathrm{ZnO}$ hybrid nanofluids. Powder Technol. 2020;363:699-716.

52. Romadhan M, Suyatma NE, Taqi FM. Synthesis of ZnO nanoparticles by precipitation method with their antibacterial effect. Indones J Chem. 2016;16(2):117-23.

53. ASTM. ASTM D7896-19, Standard Test Method for thermal conductivity, thermal diffusivity, and volumetric heat capacity of engine coolants and related fluids by transient hot wire liquid thermal conductivity method. 2019.

54. Sharifpur M, Ntumba T, Meyer JP. Parametric analysis of effective thermal conductivity models for nanofluids. In: ASME 2012 Int. Mech. Eng. Congr. Expo.; 2012. p. 1-11.

55. Wang BX, Zhou LP, Peng XF. A fractal model for predicting the effective thermal conductivity of liquid with suspension of nanoparticles. Int J Heat Mass Transf. 2003;46(14):2665-72.

56. Bruggeman VDAG. Berechnung verschiedener physikalischer Konstanten von heterogenen Substanzen. Ann Phys. 1935;5(24):636-64.

57. Okonkwo EC, Wole-Osho I, Kavaz D, Abid M. Comparison of experimental and theoretical methods of obtaining the thermal properties of alumina/iron mono and hybrid nanofluids. J Mol Liq. 2019;292:111377.

58. Hamilton RL, Crosser OK. Thermal conductivity of heterogeneous two-component systems. Ind Eng Chem Fundam. 1962;1(3):187-91.

59. Lee S, Choi SU-S, Li S, Eastman JA. Measuring thermal conductivity of fluids containing oxide nanoparticles. J Heat Transf. 1999;121(2):280-9.

60. Nielsen LE. Generalized equation for the elastic moduli of composite materials. J Appl Phys. 1970;41(11):4626-7.

61. Senthilraja S, Vijayakumar K, Gangadevi R. A comparative study on thermal conductivity of $\mathrm{Al}_{2} \mathrm{O}_{3}$ /water, $\mathrm{CuO}$ /water and $\mathrm{Al}_{2} \mathrm{O}_{3}-\mathrm{CuO} /$ water nanofluids. Dig J Nanomater Biostruct. 2015;10(4):1449-58.

62. Jang JSR. ANFIS: adaptive-network-based fuzzy inference system. IEEE Trans. Syst Man Cybern. 1993;23(3):665-85.

63. Talpur N, Salleh MNM, Hussain K. An investigation of membership functions on performance of ANFIS for solving classification problems. In: IOP Conf. Ser. Mater. Sci. Eng. 2017.

64. Handbook ASHRAE. Fundermentals (SI Edition), American Society of Heating, refrigerating and air-conditioning engineers. Atlanta: Inc.; 2009.

65. Callaway J. Model for lattice thermal conductivity at low temperatures. Phys Rev. 1959;113(4):1046.

Publisher's Note Springer Nature remains neutral with regard to jurisdictional claims in published maps and institutional affiliations. 